\title{
DNA-dependent binding of nargenicin to DnaE1 inhibits replication in
}

\section{Mycobacterium tuberculosis}

\author{
Melissa D. Chengalroyen, ${ }^{1,8}$ Mandy K. Mason, ${ }^{1,8}$ Alessandro Borsellini, ${ }^{2}$ Raffaella
}

Tassoni, ${ }^{2}$ Garth L. Abrahams, ${ }^{1,3,7}$ Sasha Lynch, ${ }^{1}$ Yong-Mo Ahn, ${ }^{3}$ Jon Ambler, ${ }^{4}$ Katherine

Young, ${ }^{5}$ Brendan M. Crowley, ${ }^{6}$ David B. Olsen, ${ }^{5}$ Digby F. Warner, ${ }^{1}$ Clifton E. Barry III, ${ }^{3}$

Helena I.M. Boshoff, ${ }^{3}$ Meindert H. Lamers, ${ }^{2 *}$ and Valerie Mizrahi ${ }^{1,9 *}$

${ }^{1}$ SAMRC/NHLS/UCT Molecular Mycobacteriology Research Unit, DST/NRF Centre of Excellence for Biomedical TB Research, Institute of Infectious Disease and Molecular Medicine and Department of Pathology, Faculty of Health Sciences, University of Cape Town, Anzio Road, Observatory 7925, South Africa.

${ }^{2}$ Cell and Chemical Biology, Leiden University Medical Center, Einthovenweg 20, 2333 ZC Leiden, The Netherlands

${ }^{3}$ Tuberculosis Research Section, Laboratory of Clinical Immunology and Microbiology, National Institute of Allergy and Infectious Disease, National Institutes of Health, 9000 Rockville Pike, Bethesda, MD 20892, USA

${ }^{4}$ Wellcome Centre for Infectious Diseases Research in Africa, University of Cape Town, Anzio Road, Observatory 7925, South Africa.

${ }^{5}$ Infectious Disease, Merck \& Co. Inc., West Point, PA 19446, USA

${ }^{6}$ Discovery Chemistry, Merck \& Co. Inc., West Point, PA 19446, USA

${ }^{7}$ Current address: Department of Biochemistry and Microbiology, Rhodes University, Grahamstown 6139, South Africa.

${ }^{8}$ These authors contributed equally

${ }^{9}$ Lead contact

*Correspondence: m.h.lamers@lumc.nl; valerie.mizrahi@uct.ac.za 


\section{SUMMARY}

Natural products provide a rich source of potential antimicrobials for use in treating infectious diseases for which drug resistance has emerged. Foremost among these is tuberculosis. Assessment of the antimycobacterial activity of nargenicin, a natural product that targets the replicative DNA polymerase of Staphylococcus aureus, revealed that it is a bactericidal genotoxin that induces a DNA damage response in Mycobacterium tuberculosis $(M t b)$ and inhibits growth by blocking the replicative DNA polymerase, DnaE1. Cryo-electron microscopy revealed that binding of nargenicin to $M t b$ DnaE1 requires the DNA substrate such that nargenicin is wedged between the terminal base pair and the polymerase and occupies the position of both the incoming nucleotide and templating base. Comparative analysis across three bacterial species suggests that the activity of nargenicin is partly attributable to the DNA binding affinity of the replicative polymerase. This work has laid the foundation for target-led drug discovery efforts focused on Mtb DnaE1.

\section{KEYWORDS}

Antimicrobial drug discovery, cryo-electron microscopy, DnaE1, DNA damage, DNA polymerase, DNA replication, DNA damage, drug resistance, Mycobacterium tuberculosis, Mycobacterium smegmatis, nargenicin

\section{INTRODUCTION}

Claiming an estimated 1.5 million lives in 2020, tuberculosis (TB) remains one of the leading causes of death globally from an infectious disease (WHO, 2021). The severe disruptions to health services wrought by the COVID-19 pandemic are predicted to worsen this grim toll by a further 1 million TB deaths per annum over the next four years (WHO, 2021). In the absence of a highly efficacious vaccine, prolonged chemotherapy with combinations of anti-TB drugs forms the cornerstone of TB control. However, the rise of drug resistance through ongoing 
evolution and spread of drug-resistant strains of the aetiologic agent, Mycobacterium tuberculosis $(M t b)$, is undermining current efforts. This problem, exacerbated by additional treatment delays caused by the pandemic, underscores the urgent need for new TB drugs with distinct mechanisms of action for inclusion in shorter, safer, and more effective drug regimens. The TB drug discovery and development pipeline established in recent years has begun to deliver new and repurposed drugs and combinations which have revolutionized the treatment of drug-resistant TB (Conradie et al., 2020), and demonstrated that treatment-shortening is an achievable goal (Dorman et al., 2021). However, maintaining this momentum requires replenishment of the pipeline with high-quality hit compounds that show mechanistic novelty (Evans and Mizrahi, 2018). This is a key objective of the Tuberculosis Drug Accelerator (TBDA) (Aldridge et al., 2021).

Of the vital cellular processes targeted by TB drugs in clinical use, DNA replication stands out as relatively under-represented (de Wet et al., 2019; Ditse et al., 2017; Reiche et al., 2017); this is despite the high vulnerability of some genes essential for DNA replication in Mtb (Bosch et al., 2021) including those encoding DNA gyrase, the target of the fluoroquinolones, moxifloxacin, gatifloxacin and levofloxacin, and the only DNA metabolic enzyme currently targeted for TB therapy. Fluoroquinolones inhibit DNA gyrase with bactericidal consequences for Mtb (Mayer and Takiff, 2014; Nagaraja et al., 2017) and have been incorporated in secondline therapy for multidrug resistant (MDR) TB (Dawson et al., 2015) and in treatmentshortening regimens for drug-susceptible TB (Dorman et al., 2021). The identification of novel scaffolds that target DNA gyrase remains an active area of investigation (Das et al., 2019; Johnson et al., 2019) while topisomerase I is also being pursued as a new TB drug target (Godbole et al., 2015). Recently, the replisome - the macromolecular machine that copies the bacterial chromosome - has emerged as an attractive potential target for TB (Ditse et al., 2017; Reiche et al., 2017) and antibacterial drug discovery, more generally (Kaguni, 2018). Key 
discoveries involving natural products have added impetus to exploring this target further: firstly, griselimycin, a cyclic depsipeptide discovered more than 50 years ago, was shown to bind with high affinity and selectivity to the $\beta$-clamp (DnaN) at the site of interaction with DNA polymerase and other DNA metabolizing enzymes (Kling et al., 2015). During DNA replication, the $\beta$-clamp interacts with DnaE1, the replicative DNA polymerase termed variously DnaE, DnaE1, or PolC in different bacteria, greatly enhancing the processivity of the polymerase. Griselimycin interferes with the protein interaction between DnaE1 and the $\beta$ clamp affecting the processivity of DNA replication (Kling et al., 2015). The mechanistic novelty of griselimycin led to the development of the analogue, cyclohexyl-griselimycin, which has improved potency and stability, and demonstrated comparable efficacy to rifampicin when used in combination with first-line drugs in a mouse infection model (Kling et al., 2015). Secondly, studies in Staphylococcus aureus identified the replicative DNA polymerase, DnaE, as the target of nargenicin A1 (referred to here as nargenicin) (Painter et al., 2015), which belongs to a class of partially saturated alicyclic polyketides comprising an octalin ring (Figure 1A) (Cane and Yang, 1985). Nargenicin is an ether-bridged macrolide antibiotic first isolated from various Nocardia species almost three decades ago (Celmer et al., 1980; Pidot and Rizzacasa, 2020). It is a narrow-spectrum antimicrobial (Painter et al., 2015) with activity against gram-positive bacteria including methicillin-resistant $S$. aureus and Micrococcus luteus (Sohng et al., 2008). The identification of narR/ngnU (Dhakal et al., 2020; Pidot and Rizzacasa, 2020), a dnaE homologue immediately adjacent to the nargenicin biosynthetic gene cluster in the producer organism, Nocardia sp. CS682 (Dhakal et al., 2019), suggested a mechanism of self-resistance to nargenicin using NarR/NgnU as a "decoy" (Pidot and Rizzacasa, 2020).

The potent bactericidal activity and low frequency of resistance for nargenicin in $S$. aureus (Painter et al., 2015) led us to investigate the antimycobacterial properties of this molecule (Young et al., 2017) under the auspices of the TBDA. Here, we show that nargenicin 
is a bactericidal genotoxin that induces a DNA damage response in $M t b$ that is accompanied by cellular elongation and potential weakening of the cell envelope. We further demonstrate that the antimycobacterial activity of nargenicin is mediated through inhibition of DNA synthesis, consistent with inhibition of the DNA polymerase activity of purified DnaE1. Structural analysis by cryo-electron microscopy (cryo-EM) revealed a unique mode of binding by nargenicin to $M t b$ DnaE1 in the presence of DNA in which nargenicin occupies the position of both the incoming nucleotide and templating base and stacks onto the terminal base pair. We show that the antibacterial efficacy of nargenicin as a DNA replication inhibitor is attributable, at least in part, to the DNA binding affinity of the organism's replicative polymerase.

\section{RESULTS}

\section{Nargenicin is bactericidal against $M t b$ in vitro}

Nargenicin was shown to have a minimum inhibitory concentration (MIC) of $12.5 \mu \mathrm{M}$ against Mtb H37Rv under standard culture conditions (7H9/OADC/Tw) (Figure 1B; Table S1). In this culture medium, nargenicin showed comparable activity against a range of drug-sensitive and drug-resistant clinical isolates of $M t b$ and was active against $M$. smegmatis (Msm). The activity against $M t b$ diminished significantly when Tween-80 was replaced by Tyloxapol to disperse the mycobacteria. This likely reflects the differential impact of these two detergents on the lipid composition of the cell envelope at the concentrations typically used for clump dispersal (Ortalo-Magne et al., 1996) with Tween-80 increasing permeability to the drug (Tullius et al., 2019). Nargenicin showed increased potency in GAST/(Fe)/Tween-80. The in vitro selectivity index was reasonable with limited cytotoxicity against the HepG2 cell line $(\mathrm{CC} 50>100 \mu \mathrm{M})$.

Time-kill kinetic analysis revealed that nargenicin was bactericidal in $M t b \mathrm{H} 37 \mathrm{Rv}$, showing time-dependent kill with limited dose dependency over the concentration range tested 
(Figure 1C). To ascertain whether this bactericidal activity was accompanied by cell lysis, we quantified GFP release from H37Rv-GFP (Chengalroyen et al., 2020; Kumar et al., 2012). Nargenicin treatment led to GFP release from day 4 onwards, peaking on day 6-7 (Figure 1D). Griselimycin treatment also resulted in delayed GFP release analogous to that elicited by nargenicin, but no release of GFP was observed upon exposure to the DNA gyrase inhibitors, ciprofloxacin or moxifloxacin, demonstrating that the GFP release was not a generic consequence of disrupting DNA metabolism (Figure 1D).

\section{Nargenicin inhibits DNA synthesis and is genotoxic in $M t b$}

To ascertain whether nargenicin shares the same mechanism of action in mycobacteria as in $S$. aureus (Painter et al., 2015), we applied a suite of complementary biological profiling assays in $M t b$ and $M s m$. Multiple attempts to isolate spontaneous nargenicin-resistant mutants in $M t b$ or $M s m$ by plating $10^{9}-10^{10}$ cells on media containing nargenicin at 5-20× $\mathrm{MIC}(M t b)$ or $1-10 \times$ MIC (Msm) were unsuccessful, yielding no heritably resistant mutants. Reasoning that nargenicin would elicit a DNA damage response if it disrupts DNA replication, we used the Mtb PrecA-LUX reporter strain to monitor activity of the DNA-damage-inducible recA promoter in response to drug treatment (Naran et al., 2016). Like fluoroquinolones and griselimycin, nargenicin triggered dose-dependent induction of luminescence (Figures $2 \mathrm{~A}$ and S1). Comparative DNA microarray analysis revealed a transcriptomic signature for nargenicintreated $M t b$ that shared key features with those elicited by mitomycin $\mathrm{C}$ and fluoroquinolones (Figure S2A, S2B and Table S2) (Boshoff et al., 2004; Boshoff et al., 2003). Genome-wide transcriptome analysis by RNA-seq revealed profound upregulation of dnaE2, imuA' and imuB, components of the mycobacterial "mutasome" responsible for DNA damage tolerance and SOS-induced mutagenesis (Boshoff et al., 2003; Warner et al., 2010), and other DNA repair genes including $r e c A$, $r a d A$, $u v r A$, $l h r$, and $a d n A B$ (Figures 2B; S2C and Data S1). Interestingly, deletion of either recA (Machowski et al., 2007) or dnaE2 (Boshoff et al., 2003; 
Warner et al., 2010) had a negligible impact on the antimycobacterial activity of nargenicin

(Table S1). Genes most highly downregulated by nargenicin were enriched in those associated with cell division ( $f t s Z$, whiB2 and ripA), and included genes involved in cell envelope biogenesis (e.g., $f b p C)$ (Figures $\mathbf{2 B}$ and S2C).

Morphological profiling of Msm exposed to nargenicin revealed a filamentation phenotype with the proportion of elongated bacilli in the population increasing with drug dose (Figure S3). This drug-induced profile clustered closely in UMAP space with those resulting from transcriptional silencing of components of the DNA replication and repair machinery (Figure 2C), as previously defined (de Wet et al., 2020), further implicating disruption of DNA metabolism in the mode of action of nargenicin. Direct evidence for inhibition of DNA replication was then obtained from a macromolecular incorporation assay, which compares incorporation of radiolabeled precursors into total nucleic acid, DNA, protein, peptidoglycan or fatty acid in cells treated with an experimental drug versus controls. Nargenicin had a profound effect on DNA synthesis resulting in $60 \%$ and $>95 \%$ reduction in $\left[{ }^{3} \mathrm{H}\right]$-uracil incorporation when used to treat $M t b$ at $2 \times$ and $20 \times$ MIC, respectively. In contrast, nargenicin had a limited impact on RNA, protein, peptidoglycan, and fatty acid synthesis (Figure 2D). Together, these results were consistent with the replicative polymerase, DnaE1, as the likely target of nargenicin in mycobacteria.

To investigate this further, we assessed the impact of modulating the level of dnaEl expression on susceptibility of mycobacteria to nargenicin. We generated a set of fluorescently labeled $M t b$ hypomorphs carrying inducible dnaEl CRISPR interference (Rock et al., 2017) constructs and determined the inhibitory activity of nargenicin against these strains in the presence or absence of the anhydrotetracycline (ATc) inducer. Marked hypersensitization to nargenicin was observed for all four hypomorphs under conditions of dnaEl silencing (+ATc) but not in the uninduced controls (-ATc) (Figures 3A-C). Notably, the effect was specific to 
nargenicin, as evidenced by the lack of effect of dnaEl silencing on the susceptibility of $M t b$ to isoniazid or ciprofloxacin, which target mycolic acid biosynthesis and DNA gyrase, respectively (Figure 3C). Together, these results identified DnaE1 as a target of nargenicin in $M t b$. Interestingly, overexpression of Msm dnaE1 had no effect on the nargenicin susceptibility in $M s m$ or Mtb (Figure S4) suggesting that DnaE1 copy number alone did not determine nargenicin efficacy.

\section{Nargenicin differentially inhibits bacterial polymerases}

Based on the microbiological evidence, we investigated whether nargenicin inhibited the DNA polymerase activity of $M t b$ DnaE1 in a biochemical assay. For comparison, we included $S$. aureus DnaE, as well as the extensively characterized replicative DNA polymerase from $E$. coli, DNA polymerase III $\alpha$ (Pol III $\alpha$ ). To monitor the polymerase activity, we used a real-time polymerase assay in which the incorporation of dGMPs in the primer strand quenches the fluorescent signal of a fluorescein group at the 5' end of the template strand (Rock et al., 2015). We found that nargenicin also inhibits the activity of $M t b$ DnaE1, albeit at $\sim 20$-fold higher concentrations than $S$. aureus $\mathrm{DnaE}$ ( $\mathrm{IC}_{50}=125 \mathrm{nM}$ and $6 \mathrm{nM}$, respectively) under the conditions of this assay (Figure 4A). Surprisingly, the E. coli polymerase was only significantly inhibited by nargenicin at concentrations higher than $10 \mu \mathrm{M}$.

\section{Cryo-EM reveals mechanism of inhibition by nargenicin}

To elucidate the mechanism of polymerase inhibition, we determined the structure of fulllength $M t b$ DnaE1 in complex with nargenicin and a DNA substrate by cryo-EM (Figures 4BF). The structure was determined to a resolution of $2.9 \AA$ with well-defined density for the polymerase active site, DNA, and the bound nargenicin molecule (Figures 4B-F). The cryoEM structure of $M t b$ DnaE1 is identical to the previously determined crystal structure (BañosMateos et al., 2017) with the exception of the oligonucleotide/oligo saccharide binding (OB) 
domain that was not included in the crystal structure (Figure S5). The OB domain is flexible as it shows a weaker density in the cryo-EM map when compared to the rest of the molecule. The flexibility of the OB domain is consistent with cryo-EM structures of E. coli Pol III $\alpha$ that show a $70 \AA$ movement of the OB-domain between the DNA-bound and DNA-free state (Fernandez-Leiro et al., 2015).

The DNA is bound in a canonical manner between the thumb and fingers domains, as was previously observed for other C-family DNA polymerases (Evans et al., 2008; FernandezLeiro et al., 2015; Wing et al., 2008). The nargenicin molecule is bound in the polymerase active site and is sandwiched between the last base pair of the DNA duplex, the first base of the template strand, and the fingers domain of the polymerase (Figure 4D). Nargenicin occupies both the position of the incoming nucleotide as well as the template base and thus mimics the position of the newly synthesized base pair (Figure 4E). To do so, the first unpaired template base is displaced from its position and bumps into Pro668 of an adjacent helix (residues 668 to 673 ) that becomes disordered. On the protein side, nargenicin occupies a shallow pocket and only makes three direct contacts with the protein: Arg667 and His787 make a hydrogen bond to two oxygens in nargenicin, while Gln638 makes a hydrogen bond with the nitrogen in the pyrrole ring (Figure 4F). The opposite end of nargenicin that is located on top of His787 makes no interaction with the protein as its nearest neighbor is over $5 \AA$ away.

The binding of nargenicin is reminiscent of the binding of aphidicolin in human DNA polymerase $\alpha$ (hPol $\alpha$ ) (Brundret et al., 1972). Although the two inhibitors are different in structure (Figure S6A) and the polymerases belong to different families (hPol $\alpha$ is a B-family polymerase, whereas Mtb DnaE1 a C-family polymerase), both inhibitors are bound between the last base pair of the DNA and the polymerase fingers domain, occupy the position of both incoming and templating base, and displace the templating base (Figure S6B-C). However, owing to the structural differences in the polymerase active sites, it is unlikely that nargenicin 
can inhibit the human polymerase as modeling of nargenicin into the hPol $\alpha$ structure reveals several clashes with the protein (Figure S6D. The similar mechanism of action of the two inhibitors derived from different organisms - aphidocolin is derived from the mold, Cephalosporium aphidicola (Brundret et al., 1972) whereas nargenicin is produced by a Nocardia species (Cane and Yang, 1985; Celmer et al., 1980) - is a remarkable case of convergent evolution.

\section{Drug resistance through allostery}

The structure described above shows that the DNA forms a crucial part of the nargenicin binding site, agreeing with the previous observation that binding of nargenicin to S. aureus DnaE only occurs in the presence of DNA (Painter et al., 2015). This DNA dependency of binding may also hold the key to the differences in inhibition between $S$. aureus DnaE, Mtb DnaE1, and E. coli Pol III $\alpha$ (Figure 5). The predicted nargenicin binding sites for S. aureus DnaE and E. coli Pol III $\alpha$ are highly similar to those of Mtb DnaE1 (Figures 5A-B) and the three residues that make a hydrogen bond with nargenicin are conserved in all three species. Hence, the difference in sensitivity does not appear to have its origin in the binding site. Moreover, a mutation in $S$. aureus DnaE (a serine to leucine mutation at position 765 , equivalent to $M t b$ DnaE1 residue 860 ) that renders it resistant to nargenicin is located $\sim 30 \AA$ away from nargenicin (Figure 5C). This mutation is immediately adjacent to the region of the fingers domain that interact with phosphate backbone of the double-stranded DNA substrate. Therefore, we hypothesized that the potency of nargenicin to inhibit a DNA polymerase may be dictated by the polymerase's affinity for DNA. To test this, we measured the DNA affinity of the three polymerases by fluorescence anisotropy using a primed DNA substrate (Figure 5D). The three polymerases show strikingly different dissociation constants of $\sim 6 \mathrm{nM}$ for $S$. aureus DnaE, $250 \mathrm{nM}$ for $M t b$ DnaE1, and $12 \mu \mathrm{M}$ for E. coli Pol III $\alpha$. These DNA affinities correlate with the relative sensitivities to nargenicin that follow the same trend (Figure $\mathbf{4 A}$ ). 
We also tested the resistant mutation in S. aureus DnaE (S765L), which, as predicted, reduced the affinity for DNA approximately 14-fold (Figure 5D).

Taken together, the data support the notion that the potential of nargenicin to inhibit a DNA polymerase is dependent on the polymerase's affinity for DNA, and any changes which reduce the DNA affinity, lead to reduced nargenicin potency, either through natural variation, as in the case of E. coli Pol III $\alpha$, or through a resistance-conferring mutation (Painter et al., 2015), as for $S$. aureus DnaE. Importantly, S. aureus engages two essential DNA polymerases at the replication fork, namely, PolC and DnaE (Inoue et al., 2001); if the activity of one is impaired, the other may compensate. However, mycobacteria rely on only one replicative polymerase, DnaE1. Therefore, nargenicin resistance-conferring mutations in DnaE1 could have catastrophic consequences in mycobacteria, which might explain our inability to isolate spontaneous resistant mutants in Mtb or Msm.

\section{DISCUSSION}

We have reported multiple lines of evidence that nargenicin acts as a DNA replication inhibitor in mycobacteria by targeting the essential DnaE1 polymerase, an enzyme identified recently as a highly vulnerable component of the DNA replication machinery in Mtb (Bosch et al., 2021). Unlike the commonly used nucleotide analogs that act as chain terminators through incorporation into the nascent DNA strand, nargenicin does not get incorporated into the DNA. Instead, it is wedged between the terminal base pair of the DNA substrate and the polymerase fingers domain, occupying both the position of the incoming nucleotide and the templating base, which is displaced by nargenicin. This binding mode is analogous to that of the human Pol $\alpha$ inhibitor, aphidicolin, which is derived from the fungus, Cephalosporium aphidicola, and unrelated in structure to nargenicin, indicating that these inhibitors have evolved independently. This unusual mechanism might explain the observation that the antimycobacterial activity of nargenicin was not diminished by over-expression of the cognate 
target, DnaE1. Based on this mechanism, the DnaE homologue in the Nocardia sp. CS682 producer organism would presumably need to bind nargenicin in a DNA-independent manner in order to fulfil its postulated "decoy" role in self-resistance (Pidot and Rizzacasa, 2020).

Nargenicin-mediated disruption of replisome function triggers a physiological response in $M t b$ which resembles that elicited by genotoxins which cause double-stranded breaks (DSBs) (mitomycin C, fluoroquinolones) (Boshoff et al., 2003). This features upregulation of genes encoding the recombinase involved in recombination repair (recA), the mutasome responsible for SOS mutagenesis and damage tolerance (dnaE2, imuA', imuB) (Boshoff et al., 2003; Warner et al., 2010), the DSB-resecting motor-nuclease ( $a d n A B)$ (Sinha et al., 2009) and a cell wall hydrolase (chiZ) (Chauhan et al., 2006), amongst other DNA-damage-responsive genes in mycobacteria. The DNA damage response to nargenicin begs the question of whether pharmacological inhibition of DnaE1 by this or other inhibitors might have the unintended consequence of inducing chromosomal mutations which could fuel the evolution of drug resistance, as documented for sub-lethal treatment of mycobacteria and other organisms by fluoroquinolones (Bush et al., 2020; Gillespie et al., 2005). This question is the subject of ongoing investigation in our laboratories. The concomitant downregulation of $f t s Z$ (de Wet $e t$ al., 2020), sepF (Gupta et al., 2015), whiB2 (Bush, 2018) and ripA (Gupta et al., 2015) is consistent with cellular elongation resulting from a block in cell division, followed by cell death. Ablation of the SOS response by deletion of $r e c A$, or a component thereof (mutasome function) by deletion of $d n a E 2$, had no impact on the antimycobacterial activity of nargenicin, suggesting that the SOS-induced DNA repair, damage tolerance and mutagenesis systems are unable to rescue mycobacteria from the growth inhibitory effects of nargenicin. Instead, an arrest in cell division, as evidenced by bacillary elongation, appears to precede cell death. Another feature of the nargenicin mode of action was the late, strong signal elicited in the GFP release assay. The induction of $c h i Z$ and downregulation of $f b p C$ might be telling in this regard: 
firstly, the damage-inducible protein, ChiZ (Burby and Simmons, 2020), been reported to arrest cell division, increase filamentation and induce cell lysis when overexpressed (Chauhan et al., 2006). Secondly, inactivation of the mycolyltransferase, FbpC, a member of the antigen 85 complex involved in the synthesis of trehalose dimycolate and mycolylarabinogalactan, which are key components of the mycobacterial cell envelope, has been shown to significantly reduce the mycolate content and increase the permeability of the cell envelope to small hydrophobic and hydrophilic molecules (Jackson et al., 1999). Thus, in addition to its replication-arresting activity, nargenicin may also compromise the integrity of the mycobacterial outer membrane and thus, act as a potentiator of other antitubercular agents whose efficacy is limited by permeation across the mycobacterial cell envelope. This intriguing possibility is the subject of active investigation in our laboratories.

In summary, the results reported here have positioned DnaE1 as a promising new TB drug target and laid the foundation for target-led drug discovery efforts focused on this enzyme.

\section{SIGNIFICANCE}

The ongoing evolution and spread of drug-resistant strains of Mycobacterium tuberculosis underscores the importance of identifying and validating new tuberculosis (TB) drug targets. In this study, we report the chemical validation of one such target, the replicative DNA polymerase, DnaE1, with the narrow-spectrum antimicrobial agent, nargenicin. We show that nargenicin mediates its bactericidal activity against $M$. tuberculosis through interaction with DnaE1 in a manner that depends upon the presence of the DNA substrate. In this interaction, the nargenicin molecule wedges itself between DnaE1 and the terminal base pair of the DNA and occupies the place of both the incoming nucleotide and the templating base. By analysing the physiological consequences of $M$. tuberculosis exposure to nargenicin, we show that the arrest in bacillary replication resulting from the nargenicin-DnaE1 interaction triggers induction of a DNA damage response coupled with an arrest in cell division and an apparent 
weakening of the mycobacterial cell envelope. In addition to strongly reaffirming the value of natural products as a source of novel antitubercular agents, this work has provided the rationale and platform for focusing target-led drug discovery efforts on a promising new TB drug target.

\section{ACKNOWLEDGEMENTS}

This work was supported by grants from the Bill \& Melinda Gates Foundation (OPP1158806 to C.E.B.III and V.M.; INV-004757 to V.M. and INV-002474 to M.H.L.), the South African Medical Research Council, the National Research Foundation of South Africa, the Oppenheimer Memorial Trust, and an International Research Scholar's grant from the HHMI (\#55007649) (to V.M.), an African Career Accelerator Award from the Crick African Network (to M.K.M.), and, in part, by the Intramural Research Program of NIAID (to H.I.M.B. and C.E.B.III). We acknowledge use of the ilifu cloud computing facility (www.ilifu.ac.za) and thank Timothy de Wet for advice and assistance with morphotyping experimentation and analysis, Dirk Schnappinger and Jeremy Rock for kindly providing reagents, and Curtis Englehart for technical advice.

\section{AUTHOR CONTRIBUTIONS}

M.D.C. and M.K.M. performed the microbiological profiling and RNA-seq experiments and analyses; G.L.A. and H.I.M.B. performed the DNA microarray and macromolecular incorporation assays; R.T. performed the polymerase assays; A.B. and M.H.L. performed the cryo-EM; J.A. provided bioinformatics support; and S.L. and Y.-M.A., provided technical support. The experiments were designed, and data analyzed, by M.D.C., M.K.M., G.L.A., B.M.C., D.B.O., D.F.W., C.E.B. III, H.I.M.B., M.H.L. and V.M. The manuscript was written by M.D.C., M.K.M., M.H.L. and V.M., and all authors read and edited it. M.H.L., D.B.O, C.E.B.III and V.M. were Team Leads. 


\section{DECLARATION OF INTERESTS}

B.M.C, K.Y. and D.B.O. are employees of Merck Sharp \& Dohme Corp., a subsidiary of Merck \& Co., Inc., Kenilworth, NJ, USA. The other authors declare no competing interests.

\section{FIGURE LEGENDS}

\section{Figure 1. Antimycobacterial activity profile of nargenicin}

(A) Chemical structure of nargenicin A1. (B) Antibacterial activity (minimal inhibitory concentration, $\mathrm{MIC}$ ) of nargenicin (NRG) in mycobacteria and other organisms illustrating the effect of media composition on activity. 7H9, Middlebrook 7H9 media; GAST/(Fe), glycerol alanine salts (with iron); Glu, glucose; (O)ADC, (oleic acid)-albumin-dextrose-catalase; Tw, Tween-80; Tx, Tyloxapol. (C) Time-kill kinetics of nargenicin in Mtb, measured by CFU enumeration. Error bars represent the SD derived from two biological replicates. Ciprofloxacin $(\mathrm{CIP} ; \mathrm{MIC}=1.5 \mu \mathrm{M})$ was used as a comparator. (D) Drug-induced lytic activity measured by release of GFP from $M t b \mathrm{H} 37 \mathrm{Rv}-\mathrm{GFP}$ at the indicated concentrations (Chengalroyen et al., 2020). Linezolid (LIN; MIC $=1.5 \mu \mathrm{M})$ and meropenem $(\mathrm{MERO} ; \mathrm{MIC}=5.2 \mu \mathrm{M})$ were used as the non-lytic and lytic controls, respectively. Data are a representative of the two biological replicates.

\section{Figure 2. Nargenicin is a genotoxin that inhibits DNA replication in mycobacteria}

(A) Analysis of recA promoter activity elicited by nargenicin using the reporter strain, PrecALUX (Naran et al., 2016). Ciprofloxacin (CIP, $2 \times$ MIC) was a positive control. RLU, relative luminescence units. (B) Volcano plot illustrating the transcriptional response (RNA-seq) of $M t b$ to nargenicin $(10 \times \mathrm{MIC})$. Differential expression $\left(\log _{2}\right.$ fold-change) of nargenicin-treated cultures versus DMSO-treated controls are plotted against adjusted P values (P-value) for each gene indicating significant upregulation of genes involved in the response of $M t b$ to DNAdamaging agents (Boshoff et al., 2003). (C) Morphological profiling of Msm in response to 
treatment with nargenicin illustrates that bacillary morphotypes (de Wet et al., 2020) cluster in UMAP space with those of CRISPRi hypomorphs in genes involved in DNA replication, including dnaE1. Black circle, untreated; black square, DMSO-treated; red circle, nargenicintreated at $1 \times$ MIC; red square, nargenicin-treated at $2 \times$ MIC; red triangle, nargenicin-treated $4 \times$ MIC. (D) Selective inhibition of DNA synthesis by nargenicin in Mtb. The incorporation of radiolabeled precursors into total nucleic acid (tNA), protein (Prot), peptidoglycan (PG), and fatty acid (FA) was measured in the absence (DMSO) or presence of nargenicin at $2 \times$ or $20 \times$ MIC (black and red bars, respectively). The level of radiolabel incorporation into each macromolecular species is depicted relative the DMSO-treated control. Assay specificity was confirmed using pathway-specific antibiotics as positive controls: ofloxacin $(5 \mu \mathrm{g} / \mathrm{mL})$, streptomycin $(10 \mu \mathrm{g} / \mathrm{mL})$, D-cycloserine $(5 \mu \mathrm{g} / \mathrm{mL})$, and isoniazid $(0.2 \mu \mathrm{g} / \mathrm{mL})$. Error bars represent the standard deviations from two experimental repeats.

\section{Figure 3. Transcriptional silencing of dnaE1 by inducible CRISPRi selectively hypersensitizes $M t b$ to nargenicin}

(A) Location of sgRNAs 3, 6, 11 and 13 on the Mtb dnaEl gene (not drawn to scale). (B) In vitro growth phenotypes of the four inducible CRISPRi hypomorphs in dnaEl constructed in a strain of $M t b$ carrying a constitutively expressed $\mathrm{mScarlet}$ reporter. Strain growth was measured using a microplate alamar blue assay after 7 days' exposure to ATc at a concentration ranging from 0.1-200 ng/ml. Columns highlighted in red represent the IC50 for ATc. Data plotted represent the average and standard deviation of two technical replicates for one of two independent experiments. (C) The four dnaE1 hypomorphs were tested for susceptibility to nargenicin (NRG) alongside the control drugs, ciprofloxacin (CIP) and isoniazid (INH). Drugmediated growth inhibition of the Mtb dnaE1 mScarlet sgRNA 3 (black), Mtb dnaE1 mScarlet 6 (green), Mtb dnaE1 mScarlet sgRNA 11 (blue), Mtb dnaE1 mScarlet sgRNA 13 (purple) 
hypomorphs, and $M t b \mathrm{mScarlet}$ vector control (red) strains in the presence (+ATc, $100 \mathrm{ng} / \mathrm{ml})$ or absence of inducer (-ATc) was determined by measuring fluorescence intensity at day 14 . Data represent the average and standard error of two technical replicates for one representative experiment, fitted with a dose response curve (nonlinear regression model). Experiments were performed in triplicate.

\section{Figure 4. Mechanism of DNA polymerase inhibition by nargenicin}

(A) Nargenicin inhibition curves of three bacterial replicative DNA polymerases, S. aureus DnaE (green line), Mtb DnaE1 (orange line), and E. coli Pol III $\alpha$ (blue line), show IC50 values of $8 \mathrm{nM}, 125 \mathrm{nM}$, and $13000 \mathrm{nM}$, respectively. (B) Cryo-EM structure of Mtb DnaE1 bound to DNA and nargenicin in yellow. (C) Magnified view of the nargenicin molecule located between the displaced template base and His787. Cryo-EM map is shown in blue mesh. (D) The composite binding site of nargenicin between the last base pair of the DNA duplex, the displaced templated base, and the fingers domain of the polymerase. (E) Top view of the binding site showing the 'base paring' of nargenicin onto the last base pair of the DNA duplex (ssDNA overhang not shown for clarity). (F) The nargenicin binding pocket in DnaE1 as viewed from the DNA. All residues located with $5 \AA$ of nargenicin are shown in green sticks. Hydrogen bonds between the protein and nargenicin are indicated with black dashed lines.

\section{Figure 5. Sensitivity to nargenicin is dependent on DNA binding affinity}

(A) Nargenicin binding site in a computational model of S. aureus DnaE. (B) Nargenicin binding site in the crystal structure of E. coli Pol III $\alpha$. Nargenicin is shown in transparent sticks and the three residues that make a hydrogen bond to nargenicin in Mtb DnaE1 are labelled (see also Figure 4F). (C) The nargenicin resistance mutation in S. aureus DnaE mapped onto Mtb DnaE1, shown by a magenta sphere, is located $30 \AA$ away from the nargenicin (shown in yellow sticks) but is adjacent to the dsDNA binding region of the polymerase. Residues that interact 
with the DNA backbone are shown in green sticks. (D) Fluorescence anisotropy DNA binding curves of $S$. aureus DnaE (green line), Mtb DnaE1 (orange line), and E. coli Pol III $\alpha$ (blue line) show dissociation constants of $6 \mathrm{nM}, 250 \mathrm{nM}$ and $12 \mu \mathrm{M}$, respectively. S. aureus $\mathrm{DnaE}^{\mathrm{S} 765 \mathrm{~L}}$ (green dashed line) which carries a mutation that confers antibiotic resistance, shows a dissociation constant of $85 \mathrm{nM}$, which is 14-fold increased, as compared to wild type. 


\begin{tabular}{|c|c|c|c|}
\hline Data collection and processing & & Model comparison & \\
\hline Magnification & $\times 105,000$ & Nonhydrogen atoms & 8990 \\
\hline Voltage (kV) & 300 & Protein residues & 1070 \\
\hline Electron exposure $\mathrm{e}^{-} / \AA^{2}$ & 54 & B factors $\left(\AA^{2}\right)$ & \\
\hline Defocus range $(\mu \mathrm{m})$ & -0.8 to -2.0 & Protein & $21-306$ \\
\hline Pixel size $(\AA)$ & 0.859 & r.m.s deviations & \\
\hline Symmetry imposed & $\mathrm{C} 1$ & Bond lengths $\left(\AA^{2}\right)$ & 0.0126 \\
\hline Initial particle images (no) & 2000000 & Bond angles $\left({ }^{\circ}\right)$ & 1.1569 \\
\hline Final particle images (no) & 196709 & Validation & \\
\hline Map resolution $(\AA)$ & 2.8 & MolProbity score & 1.47 \\
\hline FSC threshold & 1.43 & Clashscore & 4.22 \\
\hline Map resolution range $(\AA)$ & 2.8 to $>5.5$ & Poor rotamers $(\%)$ & 1.28 \\
\hline Refinement & & Ramachandran plot & \\
\hline Initial model used & $5 \mathrm{LEW}$ & Favored (\%) & 96.90 \\
\hline Model resolution $(\AA)$ & 2.9 & Allowed $(\%)$ & 3.10 \\
\hline FSC threshold & 0.143 & Disallowed (\%) & 0 \\
\hline Map sharpening $B$ factor $\left(\AA^{2}\right)$ & -50 & & \\
\hline
\end{tabular}

\section{STAR METHODS}

\section{RESOURCE AVAILABILITY}

\section{Lead Contact}

Further information and requests for resources and reagents should be directed to and will be fulfilled by the lead contact, Valerie Mizrahi (valerie.mizrahi@uct.ac.za). 


\section{Materials availability}

Plasmids and bacterial strains generated for this study are available upon request.

\section{Data and code availability}

RNA-seq datasets from this study are deposited in the NCBI Sequence Read Archive (SRA) repository (PRJNA722614) and are publicly available as of the date of publication. Atomic models and cryo-EM maps have been deposited to the Protein Data Bank and the Electron Microscopy Database under accession codes PDB XXX and EMD YYY. Accession numbers are listed in the key resources table. The paper does not report original code. The pipeline for RNA-seq analysis can be found at the GitHub repository (https://github.com/jambler24/bacterial_transcriptomics). Microscopy data are available from the lead contact upon request. Any additional information required to reanalyse the data reported in this paper is available from the lead contact upon request.

\section{EXPERIMENTAL MODEL AND SUBJECT DETAILS}

\section{Bacterial strains, culture conditions and media}

The strains used in this study are listed in the key resources table. These include the parental wildtype strains, Mtb H37Rv (Ioerger et al., 2010) and Msm mc ${ }^{2} 155$ (Snapper et al., 1990). Clinical isolates were obtained from samples collected from new TB cases and retreatment cases of subjects who were enrolled in a prospective longitudinal cohort study (ClinicalTrials.gov identifier, NCT00341601) at the National Masan Tuberculosis Hospital in the Republic of Korea from May 2005 to December 2006 (Shamputa et al., 2010). Mycobacterial strains were cultured in various media depending on the assay. 7H9 OADC was prepared by supplementing Middlebrook 7H9 (Difco) with $10 \%$ oleic acid-albumin-dextrosecatalase (OADC) enrichment (Difco), $0.2 \%$ glycerol and either $0.05 \%$ Tween-80 (7H9/OADC/Tw) or 0.05\% Tyloxypol (7H9/OADC/Tx). 7H9/Glu/ADC/Tw medium was 
prepared by substituting $10 \%$ OADC with $10 \%$ albumin-dextrose-catalase (ADC) enrichment (Difco). Similarly, 7H9/Glu/CAS/Tx was prepared by supplementing 7H9 with $0.4 \%$ glucose, $0.03 \%$ casitone (CAS), $0.081 \% \mathrm{NaCl}$ and $0.05 \%$ Tx. Glycerol-alanine-salts with iron (GASTFe/Tw) medium, $\mathrm{pH}$ 6.6, was prepared with $0.03 \% \mathrm{CAS}, 0.005 \%$ ferric ammonium citrate, $0.4 \%$ dibasic potassium phosphate, $0.2 \%$ citric acid, $0.1 \%$ L-alanine, $0.12 \% \mathrm{MgCl}_{2}, 0.06 \%$ potassium sulphate, $0.2 \%$ ammonium chloride, $0.018 \%$ of a $1 \%$ sodium hydroxide solution, $1 \%$ glycerol and $0.05 \%$ Tween-80. GAST/Tw, an iron limiting media, was made as described above, but excluding ferric ammonium citrate. All $M t b$ cultures were incubated at $37^{\circ} \mathrm{C}$ in sealed culture flasks with no agitation. Cells were plated onto Middlebrook 7H10 agar plates with $7 \mathrm{H} 10$ agar base (Difco) supplemented with $10 \%$ OADC and $0.5 \%$ glycerol. Unless indicated otherwise, microbiological assays using the strains described below were performed in 7H9/OADC/Tw media.

The fluorescent reporter strain, H37Rv-GFP (Abrahams et al., 2012), and bioluminescent reporter strain PrecA-LUX (Naran et al., 2016) were grown in media supplemented with kanamycin (Kan) at $20 \mu \mathrm{g} / \mathrm{ml}$, whereas the $M t b$ mScarlet strain and Msm $\Delta \mathrm{L}$ mutant were grown in media supplemented with hygromycin (Hyg) at $50 \mu \mathrm{g} / \mathrm{ml}$. Mtb and Msm strains carrying the $\mathrm{P}_{U V 15-T e t}-d n a E 1-M Y C::$ L5 vector (Rock et al., 2015) were grown in media containing Kan at $50 \mu \mathrm{g} / \mathrm{ml}$, and supplemented with ATc at 100ng/ml to induce expression of dnaE1. The inducible CRISPRi hypomorphs were grown in media containing Kan $(25 \mu \mathrm{g} / \mathrm{ml})$ and Hyg $(50 \mu \mathrm{g} / \mathrm{ml})$ and supplemented with ATc at $100 \mathrm{ng} / \mathrm{ml}$ to induce transcriptional silencing. Minimal inhibitory concentrations (MICs) were determined against a range of clinical isolates: Mtb CDC1551 (Valway et al., 1998); Mtb HN878 (Manca et al., 2001); drug susceptible isolates, $M t b$ 0A029, Mtb 0A031 and Mtb 0B229; multi-drug resistant isolates, $M t b$ 0B123 (resistant to isoniazid $\left(\mathrm{INH}^{\mathrm{R}}\right)$, ofloxacin $\left(\mathrm{OFX}^{\mathrm{R}}\right)$, para-amino salicylic acid $\left(\mathrm{PAS}^{\mathrm{R}}\right)$, streptomycin $\left(\mathrm{STR}^{\mathrm{R}}\right)$, rifampicin $\left(\mathrm{RIF}^{\mathrm{R}}\right) ; M t b 0 \mathrm{~A} 024\left(\right.$ ethambutol $\left(\mathrm{EMB}^{\mathrm{R}}\right), \mathrm{INH}^{\mathrm{R}}$, 
$\mathrm{KAN}^{\mathrm{R}}, \mathrm{PAS}^{\mathrm{R}}$, pyrazinamide $\left(\mathrm{PZA}^{\mathrm{R}}\right), \mathrm{STR}^{\mathrm{R}}$, ethionamide $\left.\left(\mathrm{ETH}^{\mathrm{R}}\right), \mathrm{RIF}^{\mathrm{R}}\right), M t b 0 \mathrm{~B} 026\left(\mathrm{EMB}^{\mathrm{R}}\right.$,

$\left.\mathrm{INH}^{\mathrm{R}}, \mathrm{KAN}^{\mathrm{R}}, \mathrm{PAS}^{\mathrm{R}}, \mathrm{RIF}^{\mathrm{R}}\right)$; and an extensively drug resistant strain, $M t b 0 \mathrm{~B} 014\left(\mathrm{EMB}^{\mathrm{R}}, \mathrm{INH}^{\mathrm{R}}\right.$, $\left.\mathrm{KAN}^{\mathrm{R}}, \mathrm{OFX}^{\mathrm{R}}, \mathrm{PAS}^{\mathrm{R}}, \mathrm{RIF}^{\mathrm{R}}\right)($ Shamputa et al., 2010).

\section{METHOD DETAILS}

\section{Drug susceptibility testing}

MIC testing was performed by broth microdilution assay (Abrahams et al., 2012) and quantitatively analyzed with the colorimetric alamarBlue cell viability reagent (Thermo Fischer Scientific), as previously described (Chengalroyen et al., 2020).

\section{Bioluminescence assay}

PrecA-LUX (Naran et al., 2016) was grown to an $\mathrm{OD}_{600} \sim 0.4$, diluted 10-fold in 7H9/OADC/Tw and inoculated into white, clear-bottom, 96-well microtiter plates (Greiner CellStar ${ }^{\circledR}$ ) containing a two-fold serial dilutions of drug. Plates were incubated at $37^{\circ} \mathrm{C}$ and luminescence recorded every 24 h for 8 days using a SpectraMax i3x plate reader (Molecular Devices). Data were plotted in Prism 9 (GraphPad).

\section{GFP release assay}

As described previously (Chengalroyen et al., 2020), H37Rv-GFP was grown to an OD 600 of $\sim 0.3$ in $7 \mathrm{H} 9 \mathrm{OADC}$ and exposed to drug at $1 \times$ or $10 \times \mathrm{MIC}$. Every $24 \mathrm{~h}$, over a period of 8 days, $200 \mu \mathrm{l}$ of culture was harvested, pelleted by centrifugation, and the supernatant transferred to a black, clear-bottom 96-well microtitre plate (Greiner CellStar ${ }^{\circledR}$ ) and fluorescence (excitation, $540 \mathrm{~nm}$; emission, $590 \mathrm{~nm}$ ) measured using a SpectraMax i3x plate reader (Molecular Devices). Fluorescence intensity was normalized by $\mathrm{OD}_{650}$ and standardized to the value of the drug-free control for each sample.

\section{Time-kill kinetics}


$M t b$ was inoculated in culture medium at an $\mathrm{OD}_{600}$ of 0.002 and drug added at a concentration of either $1 \times, 5 \times$ or $10 \times$ MIC. Cultures were incubated in sealed culture flasks and $1 \mathrm{ml}$ aliquots harvested every 24 h over 8 days. The samples were washed twice in fresh media. One hundred $\mu \mathrm{l}$ aliquots of 10-fold serial dilutions were plated of 7H11 agar and colony forming units (CFUs) enumerated after incubation for 3-4 weeks.

\section{Macromolecular incorporation assays}

Macromolecular incorporation assays were performed as described (Barrow et al., 2003; Cotsonas King and Wu, 2009). Briefly, Mtb cultures were grown to early exponential phase $\left(\mathrm{OD}_{600} \sim 0.3\right)$ and $1 \mu \mathrm{Ci} / \mathrm{ml}\left[{ }^{3} \mathrm{H}\right]$-uracil, $2.5 \mu \mathrm{Ci} / \mathrm{ml}[3 \mathrm{H}]$-phenylalanine, $10 \mu \mathrm{Ci} / \mathrm{ml}\left[{ }^{3} \mathrm{H}\right]-\mathrm{N}-$ acetyl glucosamine, and $1 \mu \mathrm{Ci} / \mathrm{ml}\left[{ }^{14} \mathrm{C}\right]$-acetate added to quantify the incorporation of the radiolabeled precursors into either total nucleic acid (i.e., DNA and RNA), protein, cell wall, and fatty acids, respectively. Cells were incubated at $37^{\circ} \mathrm{C}$ for $1 \mathrm{~h}$ and $150 \mu \mathrm{l}$ transferred to 96well microtiter plates containing $150 \mu \mathrm{l}$ of each test compound. Nargenicin was used at $2 \times$ and 20x MIC with $1 \%$ DMSO included as an untreated control. The specificity of assays was monitored by the inclusion of the pathway-specific antibiotics OFX $(5 \mu \mathrm{g} / \mathrm{mL})$, STR (10 $\mu \mathrm{g} / \mathrm{mL}$ ), D-cycloserine (DCS, $5 \mu \mathrm{g} / \mathrm{mL})$, and INH $(0.2 \mu \mathrm{g} / \mathrm{mL})$ as positive controls. The assay plates were incubated at $37^{\circ} \mathrm{C}$ for $24 \mathrm{~h}$ and precursor incorporation terminated by the addition of $300 \mu \mathrm{l}$ of $20 \%$ trichloroacetic acid (TCA). The samples were incubated at $4{ }^{\circ} \mathrm{C}$ for $1 \mathrm{~h}$ and the precipitates collected by vacuum filtration with a 96-well MultiScreen GFC glass fiber plate (Millipore). Precipitates were washed three times with $10 \%$ TCA followed by three 95\% ethanol washes and the plates allowed to air dry. Precipitates were resuspended in $50 \mu 1$ MicroScint 20 (PerkinElmer) and the radioactivity on each filter measured in a MicroBeta Liquid Scintillation Counter (PerkinElmer). To distinguish between the incorporation of $\left[{ }^{3} \mathrm{H}\right]-$ uracil into DNA vs. RNA, the RNA was hydrolyzed with $500 \mu \mathrm{l}$ of $1 \mathrm{M} \mathrm{KOH}$ at $37^{\circ} \mathrm{C}$ for $16 \mathrm{~h}$ 
and neutralized with $125 \mu \mathrm{HCl}$. Samples were then precipitated by adding $625 \mu 120 \%$ TCA and the amount of residual radioactivity present in the DNA precipitates quantified following filtration and washing as described above. All samples were analyzed in duplicate, and results represent the percentage of radiolabel incorporation relative to the DMSO-treated control from two independent replicates.

\section{Microscopy}

Msm bacilli were imaged to determine their terminal phenotypes under exposure to varying concentrations of antibiotic as previously described (de Wet et al., 2020). Strains were grown to late-log phase $\left(\mathrm{OD}_{600} \sim 0.8\right)$, filtered once through a Millex syringe filter (5 $\mu \mathrm{m}$ pore size, Millipore) and diluted 1:40 into fresh media. Samples were left untreated, exposed to carrier (DMSO only), or to varying concentrations of nargenicin in DMSO $(1 \times \mathrm{MIC}, 2 \times \mathrm{MIC}, 4 \times$ MIC) and incubated for $18 \mathrm{~h}$ at $37^{\circ} \mathrm{C}$ while shaking. After exposure cultures were spotted onto low-melt agarose pads and imaged on a ZEISS Axio Observer using a 100×, 1.4 na Objective with Phase Contrast and Colibri 7 fluorescent illumination system. Images were captured using a Zeiss Axiocam 503. Image processing, cell measurements and analysis were performed in the FIJI Plugin MicrobeJ (Ducret et al., 2016; Schindelin et al., 2012), R (R Core Team, 2020; RStudio Team, 2020) and UMAP as described (de Wet et al., 2020).

\section{Transcriptional profiling}

Microarray experiments and analyses were performed by the NIAID Microarray Research Facility, as previously described (Boshoff et al., 2003), including two independent samples for each treatment condition. Datasets from cultures exposed to mitomycin $C(0.2 \mu \mathrm{g} / \mathrm{ml})$, and levofloxacin $(10 \mu \mathrm{g} / \mathrm{ml})$ were compared to nargenicin $(129 \mu \mathrm{g} / \mathrm{ml})$. The top 300 upregulated or downregulated genes, ranked by the average $\log 2$ fold-change in expression data from two biological repeats, were compared to generate gene shortlists common to all three treatments. 
For RNA-seq, qRT-PCR and microarray experiments, $M t b$ cultures $(20-30 \mathrm{ml})$ were grown either in roller bottles or in culture flasks on a shaker to mid-exponential phase (OD 600 $\sim 0.3-0.5)$ prior to treatment with nargenicin at $1 \times$ or $10 \times$ MIC for $6 \mathrm{~h}$. Cells were harvested by centrifugation at $3000 \times g$ for $10 \mathrm{~min}$ and resuspended in $1 \mathrm{ml}$ Qiazol Lysis Reagent (Qiagen). Cells were lysed with $0.1 \mathrm{~mm}$ Zirconia/Silica beads (BioSpec) in a MagNA Lyser Homogenizer (Roche) (6000 rpm, 30 s) three times with 1 min cooling intervals. Samples were centrifuged at $10000 \times \mathrm{g}$ for $5 \mathrm{~min}$ at $4^{\circ} \mathrm{C}$ and the supernatant transferred into a clean tube containing an equal volume of $100 \%$ ethanol. The RNA was purified and treated with DNase on-column using the Direct-zol RNA MiniPrep kit (Zymo Research) according to the manufacturer's protocol. Samples were eluted in $50 \mu \mathrm{l}$ of RNase- and DNase-free water. Purified RNA was treated with DNase for an additional 60 min at $37^{\circ} \mathrm{C}$ using the TURBO DNA-free kit (Ambion) according to the manufacturer's protocol. In preparation for microarray analysis and RNA-seq, the sample quality was confirmed using a Bioanalyzer RNA 6000 Nano Kit and Chips (Agilent). For RNA-seq experiments, three independent biological replicates of both nargenicin-treated $(10 \times \mathrm{MIC})$ and untreated samples were performed. Library preparation and sequencing was done by Admera Health (NJ, USA) using the Illumina NovaSeq S4 sequencing platform. The sequencing strategy included an average of 60 million $150 \mathrm{bp}$ paired end reads per sample. Reads were demultiplexed to generate raw fastq files for each sample and data deposited in the NCBI SRA repository (PRJNA722614). Initial quality control (QC) of the raw fastQ files was performed using FastQC (Andrews, 2010). Reads were trimmed and adapters removed using Trim Galore. Further QC was done by aligning reads using BWA to the reference genome of Mtb H37Rv, ASM19595v2, GenBank assembly accession no. GCA_000195955.2 (https://www.ncbi.nlm.nih.gov/assembly/GCF_000195955.2), running RSeQC (Wang et al., 2016) and dupRadar (Sayols et al., 2016), and an amalgamated report generated using MultiQC 
(Ewels et al., 2016). Transcript quantification was performed using Salmon in mapping-based mode (Patro et al., 2017). Normalization and differential expression analysis were done using DESeq2 (Love et al., 2014) with count normalization by DESeq2's median or ratios. $P$-values were adjusted for multiple-testing using the Benjamini-Hochberg approach, and genes which displayed an absolute $\log 2$ fold-change $>1$ and an adjusted $p$-value $<0.05$ were considered differentially expressed. Data were visualized in $\mathrm{R}$ and functional enrichment of upregulated and downregulated shortlists as compared to the full genome was performed in STRING (Szklarczyk et al., 2018) using Gene Ontologies, STRING local network clusters, annotated keywords, KEGG pathways and InterPro protein domains and features as categories. Multiple comparisons were compensated for using the false discovery rate (FDR), with significant enrichment considered as FDR $>0.05$.

For qRT-PCR experiments, following TURBO DNase treatment, 250 ng of the RNA was converted to cDNA using SuperScript ${ }^{\circledR}$ IV Reverse Transcriptase (Thermo Fischer Scientific). Regions of interest were amplified using primer pairs described in Table S3 and Power SYBR® Green PCR master mix (Thermo Fischer Scientific) and transcript levels for three independent samples quantified on a PikoReal real-time PCR system (Thermo Fischer Scientific). Transcript levels of target genes were normalized to sigA.

\section{Construction of fluorescent dnaE1 hypomorphs}

The ATc-regulated CRISPRi system developed by Rock et al. (2017) was used to construct inducible dnaEl-targeting Mtb hypomorphs carrying the mScarlet fluorescence reporter (Kolbe et al., 2020) (see key resources table). Briefly, two oligonucleotides complementary to the dnaE1 targeting sequence (Table S3) were annealed and cloned in pLJR965, and the presence of the sgRNA confirmed by Sanger sequencing. The sequence-verified constructs were electroporated into $M t b \mathrm{mScarlet}$, selecting on media supplemented with Kan $(25 \mu \mathrm{g} / \mathrm{ml})$ and Hyg $(50 \mu \mathrm{g} / \mathrm{ml})$. 


\section{Drug susceptibility testing using hypomorphs}

To assess the impact of dnaEl silencing on drug susceptibility, the hypomorphs and vector control strains were grown to an $\mathrm{OD}_{600}$ of 1.0 and diluted to an $\mathrm{OD}_{600}$ of 0.01 in media either with ATc $(200 \mathrm{ng} / \mathrm{ml})$ or without the inducer. Fifty $\mu \mathrm{l}$ of the diluted culture was inoculated into each well of a MIC plate containing $50 \mu \mathrm{l}$ of media with 2-fold dilutions of drug. Microtitre plates were incubated at $37^{\circ} \mathrm{C}$ for 14 days and the fluorescence $(594 \mathrm{~nm}$, excitation; and 569 $\mathrm{nm}$, emission) recorded using a Spectramax i3x plate reader. Each strain was normalized to the no-drug control to determine the percentage growth inhibition as a function of drug concentration. Dose-response curves were plotted in Prism 9 (GraphPad).

\section{Protein expression and purification}

$M t b$ DnaE1 was expressed in Msm and purified as previously described (Rock et al., 2015). S. aureus DnaE and E. coli Pol III $\alpha$ were expressed in E. coli BL21 and purified as previously described (Painter et al., 2015; Toste Rego et al., 2013).

\section{DNA polymerase assay}

DNA polymerase activity was measured using a real-time polymerase assay as described previously (Rock et al., 2015). Briefly, reactions were performed using $5 \mathrm{nM}$ DNA polymerase, $10 \mathrm{nM}$ of fluorescently labelled DNA substrate (Primer: 5'TAGGACGAAGGACTCCCAACTTAGGTGCG, Template: 6-FAM-5'CCCCCCCCCATGCATGCGCACCTAAAGTTGGGAGTCCTTCGTCCTA) and $100 \mathrm{nM}$ of unlabeled DNA substrate (same sequence as above). Reactions contained $100 \mu \mathrm{M}$ of each dNTP, $5 \mathrm{mM} \mathrm{MgSO}_{4}, 50 \mathrm{mM}$ HEPES $\mathrm{pH}$ 7.5, $100 \mathrm{mM}$ potassium glutamate, $2 \mathrm{mM}$ DTT, 0.5 $\mathrm{mg} / \mathrm{ml} \mathrm{BSA}$ and $10 \mathrm{nM}-10 \mu \mathrm{M}$ nargenicin. $10 \mu \mathrm{L}$ reactions were measured for 20 minutes at $24{ }^{\circ} \mathrm{C}$ in a 384-well plate using a Clariostar plate reader (BMG LABTECH) with excitation and emission filters at 485 and $520 \mathrm{~nm}$, respectively. 


\section{Fluorescence anisotropy}

DNA binding was measured using $5 \mathrm{nM}$ of a Cy3-labelled DNA substrate (Primer: Cy3-5'GGTAACGCCAGGGTTTTCCCAGTC3, Template

\section{CGCTCACTGGCCGTCGTTTTACAACGTCGTGACTGGGAAAACCCTGGCGTTACC)}

and $1 \mathrm{nM}-40 \mu \mathrm{M}$ DNA polymerase. Reactions conditions contained $25 \mathrm{mM}$ HEPES pH 7.5, $50 \mathrm{mM}$ potassium glutamate, $2 \mathrm{mM}$ DTT, $0.5 \mathrm{mg} / \mathrm{ml} \mathrm{BSA.} 10 \mu \mathrm{L}$ reactions were measured at $24{ }^{\circ} \mathrm{C}$ in a 384-well plate using a Clariostar plate reader with excitation and emission filters at 540 and $590 \mathrm{~nm}$, respectively.

\section{Cryo-EM sample preparation and imaging}

Purified $M t b$ DnaE1 was diluted to $4 \mu \mathrm{M}$ in $20 \mathrm{mM}$ PIPES pH 7.0, $50 \mathrm{mM}$ potassium glutamate, $5 \mathrm{mM} \mathrm{MgCl} 2,2 \mathrm{mM}$ DTT, and $0.01 \%$ Tween-20. The diluted protein was incubated for $5 \mathrm{~min}$ with $20 \quad \mu \mathrm{M} \quad$ DNA substrate $\quad$ (Template: GAtAGAGCAGAAGGACGAAGGACTCCCAACTTTAGGTG, Primer: 5'GCACCTAAAGTTGGGAGTCCTTCGTCCT*T, where the asterisk marks the position of a phosphorothioate bond). Three $\mu$ l of sample were adsorbed onto glow-discharged copper R2/1 holey carbon grids (Quantifoil). Grids were glow discharged 45 seconds at $25 \mathrm{~mA}$ using an EMITECH K950 apparatus. Grids were blotted for one second at $\sim 80 \%$ humidity at $4{ }^{\circ} \mathrm{C}$ and flash frozen in liquid ethane using a Leica EM GP plunge freezer. The grids were loaded into a Titan Krios (FEI) electron microscope operating at $300 \mathrm{kV}$ with a Gatan $\mathrm{K} 3$ detector. The slit width of the energy filter was set to $20 \mathrm{eV}$. Images were recorded with EPU software (Thermo Fisher Scientific) in counting mode. Dose, magnification, and pixel size are detailed in Table 1.

\section{Cryo-EM image processing}


All image processing was performed using RELION 3.1 (Zivanov et al., 2018). The images were drift corrected using RELION's own (CPU-based) implementation of the UCSF motioncor2, and defocus was estimated using gCTF (Zhang, 2016). LoG-based auto-picking was performed on all micrographs and picked particles were 2D classified. After three rounds of 2D classification, classes with different orientations were selected for initial model generation in RELION. The initial model was used as reference for 3D classification into different classes. The selected classes from 3D classification were subjected to 3D auto refinement followed by different rounds of CTF refinement plus a final round of Bayesian polishing. Polished particles were used for 3D auto-refine job and the final map was postprocessed to correct for modulation transfer function of the detector and sharpened by applying a negative B-factor manually set to -50 . A soft mask was applied during post processing to generate FSC curves to yield a map of average resolution of $2.9 \AA$. The RELION postprocessed map was used to generate improved-resolution EM maps using the SuperEM method (Subramaniya et al., 2021), which aided in model building and refinement. Model building was performed using Coot (Emsley et al., 2010), REFMAC5 (Murshudov et al., 2011), the CCPEMsuite (Nicholls et al., 2018) and Phenix (Liebschner et al., 2019). Details on model refinement and validation are shown in Table 1. In brief, model building started by rigid-body fitting of the known DnaE1 crystal structure (PDB 5LEW) (Baños-Mateos et al., 2017) into experimental density map using Coot. The DNA molecule was generated, and rigid body fitted into experimental density map using Coot. Next, we carried out one round of refinement in REFMAC5 using jelly-body restraints, and the model was further manually adjusted in Coot. Final refinement and model validation were performed using Phenix.

\section{Quantification and statistical analysis}

Statistical details are given in methods sections and figure legends, these include details of the experiments, numbers of replicates (technical and/or experimental), statistical software used 
and thresholds of significance. Significance was generally determined as $\mathrm{p}<0.05$ and correction for multiple comparisons was performed, as appropriate. Independent experiments were performed a minimum of two times and these data were utilised for the generation of summary statistics (mean and standard deviation). Replicate data are included within each figure, as indicated in figure legends, else data are described as a representative experiment. In addition, DNA polymerase assays and DNA binding experiments were performed in three or more independent experiments. Data were not excluded from experimental datasets prior to or during analyses other than during cryo-EM data processing, where particles that did not possess high resolution features were removed following standard procedures for cryo-EM structure determination.

\section{SUPPLEMENTAL ITEMS}

Document S1. Figures S1-S6 and Tables S1-S3

Data S1. Dataset S1 comprising output genelists of RNA-seq differential gene expression analysis and STRING functional analysis of significantly differentially expressed genes. Related to Figure 2 and Figure 2C.

\section{REFERENCES}

Abrahams, G.L., Kumar, A., Savvi, S., Hung, A.W., Wen, S., Abell, C., Barry, C.E., 3rd, Sherman, D.R., Boshoff, H.I., and Mizrahi, V. (2012). Pathway-selective sensitization of Mycobacterium tuberculosis for target-based whole-cell screening. Chem Biol 19, 844-854. 10.1016/j.chembiol.2012.05.020.

Aldridge, B.B., Barros-Aguirre, D., Barry, C.E., Bates, R.H., Berthel, S.J., Boshoff, H.I., Chibale, K., Chu, X.-J., Cooper, C.B., Dartois, V., et al. (2021). The Tuberculosis Drug Accelerator at year 10: what have we learned? Nature Medicine 27, 1333-1337. 10.1038/s41591-021-01442-2.

Andrews, S. (2010). FastQC: A quality control tool for high throughput sequence data.

Baños-Mateos, S., van Roon, A.-M.M., Lang, U.F., Maslen, S.L., Skehel, J.M., and Lamers, M.H. (2017). High-fidelity DNA replication in Mycobacterium tuberculosis relies on a trinuclear zinc center. Nat Commun 8, 855. 10.1038/s41467-017-00886-w. 
Barrow, E.W., Westbrook, L., Bansal, N., Suling, W.J., Maddry, J.A., Parker, W.B., and Barrow, W.W. (2003). Antimycobacterial activity of 2-methyl-adenosine. J Antimicrob Chemother 52, 801-808. 10.1093/jac/dkg444.

Bosch, B., DeJesus, M.A., Poulton, N.C., Zhang, W., Engelhart, C.A., Zaveri, A., Lavalette, S., Ruecker, N., Trujillo, C., Wallach, J.B., et al. (2021). Genome-wide gene expression tuning reveals diverse vulnerabilities of $\mathrm{M}$. tuberculosis. Cell 184, 4579-4592 e4524. 10.1016/j.cell.2021.06.033.

Boshoff, H.I., Myers, T.G., Copp, B.R., McNeil, M.R., Wilson, M.A., and Barry, C.E., 3rd (2004). The transcriptional responses of Mycobacterium tuberculosis to inhibitors of metabolism: novel insights into drug mechanisms of action. J Biol Chem 279, 40174-40184. 10.1074/jbc.M406796200.

Boshoff, H.I., Reed, M.B., Barry, C.E., 3rd, and Mizrahi, V. (2003). DnaE2 polymerase contributes to in vivo survival and the emergence of drug resistance in Mycobacterium tuberculosis. Cell 113, 183-193. 10.1016/s0092-8674(03)00270-8.

Brundret, K.M., Dalziel, W., Hesp, B., Jarvis, J.A.J., and Neidle, S. (1972). X-Ray crystallographic determination of the structure of the antibiotic aphidicolin: a tetracyclic diterpenoid containing a new ring system. Journal of the Chemical Society, Chemical Communications, 1027-1028. 10.1039/C39720001027.

Burby, P.E., and Simmons, L.A. (2020). Regulation of cell division in bacteria by monitoring genome integrity and DNA replication status. J Bacteriol 202. 10.1128/JB.00408-19.

Bush, M.J. (2018). The actinobacterial WhiB-like (Wbl) family of transcription factors. Mol Microbiol 110, 663-676. 10.1111/mmi.14117.

Bush, N.G., Diez-Santos, I., Abbott, L.R., and Maxwell, A. (2020). Quinolones: Mechanism, lethality and their contributions to antibiotic resistance. Molecules 25. $10.3390 /$ molecules 25235662 .

Cane, D.E., and Yang, C.C. (1985). Nargenicin biosynthesis: late stage oxidations and absolute configuration. J Antibiot (Tokyo) 38, 423-426. 10.7164/antibiotics.38.423.

Celmer, W.D., Chmurny, G.N., Moppett, C.E., Ware, R.S., Watts, P.C., and Whipple, E.B. (1980). Structure of natural antibiotic CP-47,444. J Am Chem Soc 102, 4203-4209. 10.1021/ja00532a036.

Chauhan, A., Lofton, H., Maloney, E., Moore, J., Fol, M., Madiraju, M.V., and Rajagopalan, M. (2006). Interference of Mycobacterium tuberculosis cell division by Rv2719c, a cell wall hydrolase. Mol Microbiol 62, 132-147. 10.1111/j.1365-2958.2006.05333.x.

Chengalroyen, M.D., Jordaan, A., Seldon, R., Ioerger, T., Franzblau, S.G., Nasr, M., Warner, D.F., and Mizrahi, V. (2020). Biological profiling enables rapid mechanistic classification of phenotypic screening hits and identification of KatG activation-dependent pyridine carboxamide prodrugs with activity against Mycobacterium tuberculosis. Front Cell Infect Microbiol 10. 10.3389/fcimb.2020.582416.

Conradie, F., Diacon, A.H., Ngubane, N., Howell, P., Everitt, D., Crook, A.M., Mendel, C.M., Egizi, E., Moreira, J., Timm, J., et al. (2020). Treatment of highly drug-resistant pulmonary tuberculosis. New England Journal of Medicine 382, 893-902. 10.1056/NEJMoa1901814.

Cotsonas King, A., and Wu, L. (2009). Macromolecular synthesis and membrane perturbation assays for mechanisms of action studies of antimicrobial agents. Curr Protoc Pharmacol Chapter 13, Unit 13A 17. 10.1002/0471141755.ph13a07s47. 
Das, S., Garg, T., Srinivas, N., Dasgupta, A., and Chopra, S. (2019). Targeting DNA gyrase to combat Mycobacterium tuberculosis: An update. Curr Top Med Chem 19, 579-593. $10.2174 / 1568026619666190304130218$.

Dawson, R., Diacon, A.H., Everitt, D., van Niekerk, C., Donald, P.R., Burger, D.A., Schall, R., Spigelman, M., Conradie, A., Eisenach, K., et al. (2015). Efficiency and safety of the combination of moxifloxacin, pretomanid (PA-824), and pyrazinamide during the first 8 weeks of antituberculosis treatment: a phase $2 \mathrm{~b}$, open-label, partly randomised trial in patients with drug-susceptible or drug-resistant pulmonary tuberculosis. Lancet 385, 1738-1747. 10.1016/S0140-6736(14)62002-X.

de Wet, T.J., Warner, D.F., and Mizrahi, V. (2019). Harnessing biological insight to accelerate tuberculosis drug discovery. Acc Chem Res 52, 2340-2348. 10.1021/acs.accounts.9b00275.

de Wet, T.J., Winkler, K.R., Mhlanga, M., Mizrahi, V., and Warner, D.F. (2020). Arrayed CRISPRi and quantitative imaging describe the morphotypic landscape of essential mycobacterial genes. elife 9. 10.7554/eLife.60083.

Dhakal, D., Han, J.M., Mishra, R., Pandey, R.P., Kim, T.S., Rayamajhi, V., Jung, H.J., Yamaguchi, T., and Sohng, J.K. (2020). Characterization of tailoring steps of nargenicin A1 biosynthesis reveals a novel analogue with anticancer activities. ACS Chem Biol 15, 13701380. 10.1021/acschembio.9b01034.

Dhakal, D., Rayamajhi, V., Nguyen, H.T., Poudel, P.B., and Sohng, J.K. (2019). Complete genome sequence of Nocardia sp. strain CS682, a producer of antibacterial compound nargenicin A1. Microbiol Resour Announc 8. 10.1128/MRA.01098-19.

Ditse, Z., Lamers, M.H., and Warner, D.F. (2017). DNA replication in Mycobacterium tuberculosis. Microbiol Spectr 5, TBTB20027-22016. 10.1128/microbiolspec.TBTB2-00272016.

Dorman, S.E., Nahid, P., Kurbatova, E.V., Phillips, P.P.J., Bryant, K., Dooley, K.E., Engle, M., Goldberg, S.V., Phan, H.T.T., Hakim, J., et al. (2021). Four-month rifapentine regimens with or without moxifloxacin for tuberculosis. New England Journal of Medicine 384, 17051718. 10.1056/NEJMoa2033400.

Ducret, A., Quardokus, E.M., and Brun, Y.V. (2016). MicrobeJ, a tool for high throughput bacterial cell detection and quantitative analysis. Nat Microbiol 1, 16077. 10.1038/nmicrobiol.2016.77.

Emsley, P., Lohkamp, B., Scott, W.G., and Cowtan, K. (2010). Features and development of Coot. Acta Crystallogr D Biol Crystallogr 66, 486-501. 10.1107/S0907444910007493.

Evans, J.C., and Mizrahi, V. (2018). Priming the tuberculosis drug pipeline: new antimycobacterial targets and agents. Curr Opin Microbiol 45, 39-46. 10.1016/j.mib.2018.02.006.

Evans, R.J., Davies, D.R., Bullard, J.M., Christensen, J., Green, L.S., Guiles, J.W., Pata, J.D., Ribble, W.K., Janjic, N., and Jarvis, T.C. (2008). Structure of PolC reveals unique DNA binding and fidelity determinants. Proc Natl Acad Sci U S A 105, 20695-20700. 10.1073/pnas.0809989106.

Ewels, P., Magnusson, M., Lundin, S., and Käller, M. (2016). MultiQC: summarize analysis results for multiple tools and samples in a single report. Bioinformatics 32, 3047-3048. 10.1093/bioinformatics/btw354. 
Fernandez-Leiro, R., Conrad, J., Scheres, S.H., and Lamers, M.H. (2015). cryo-EM structures of the E. coli replicative DNA polymerase reveal its dynamic interactions with the DNA sliding clamp, exonuclease and tau. elife 4. 10.7554/eLife.11134.

Gillespie, S.H., Basu, S., Dickens, A.L., O'Sullivan, D.M., and McHugh, T.D. (2005). Effect of subinhibitory concentrations of ciprofloxacin on Mycobacterium fortuitum mutation rates. J Antimicrob Chemother 56, 344-348. 10.1093/jac/dki191.

Godbole, A.A., Ahmed, W., Bhat, R.S., Bradley, E.K., Ekins, S., and Nagaraja, V. (2015). Targeting Mycobacterium tuberculosis topoisomerase I by small-molecule inhibitors. Antimicrob Agents Chemother 59, 1549-1557. 10.1128/aac.04516-14.

Gupta, S., Banerjee, S.K., Chatterjee, A., Sharma, A.K., Kundu, M., and Basu, J. (2015). Essential protein SepF of mycobacteria interacts with FtsZ and MurG to regulate cell growth and division. Microbiology 161, 1627-1638. 10.1099/mic.0.000108.

Inoue, R., Kaito, C., Tanabe, M., Kamura, K., Akimitsu, N., and Sekimizu, K. (2001). Genetic identification of two distinct DNA polymerases, DnaE and PolC, that are essential for chromosomal DNA replication in Staphylococcus aureus. Mol Genet Genomics 266, 564-571. $10.1007 / \mathrm{s} 004380100564$.

Ioerger, T.R., Feng, Y., Ganesula, K., Chen, X., Dobos, K.M., Fortune, S., Jacobs, W.R., Jr., Mizrahi, V., Parish, T., Rubin, E., et al. (2010). Variation among genome sequences of H37Rv strains of Mycobacterium tuberculosis from multiple laboratories. J Bacteriol 192, 3645-3653. 10.1128/JB.00166-10.

Jackson, M., Raynaud, C., Lanéelle, M.A., Guilhot, C., Laurent-Winter, C., Ensergueix, D., Gicquel, B., and Daffé, M. (1999). Inactivation of the antigen $85 \mathrm{C}$ gene profoundly affects the mycolate content and alters the permeability of the Mycobacterium tuberculosis cell envelope. Mol Microbiol 31, 1573-1587. 10.1046/j.1365-2958.1999.01310.x.

Johnson, E.O., LaVerriere, E., Office, E., Stanley, M., Meyer, E., Kawate, T., Gomez, J.E., Audette, R.E., Bandyopadhyay, N., Betancourt, N., et al. (2019). Large-scale chemicalgenetics yields new M. tuberculosis inhibitor classes. Nature 571, 72-78. 10.1038/s41586-0191315-z,.

Kaguni, J.M. (2018). The macromolecular machines that duplicate the Escherichia coli chromosome as targets for drug discovery. Antibiotics (Basel) 7. 10.3390/antibiotics7010023.

Kling, A., Lukat, P., Almeida, D.V., Bauer, A., Fontaine, E., Sordello, S., Zaburannyi, N., Herrmann, J., Wenzel, S.C., König, C., et al. (2015). Antibiotics. Targeting DnaN for tuberculosis therapy using novel griselimycins. Science 348, 1106-1112. 10.1126/science.aaa4690.

Kolbe, K., Bell, A.C., Prosser, G.A., Assmann, M., Yang, H.-J., Forbes, H.E., Gallucci, S., Mayer-Barber, K.D., Boshoff, H.I., and Barry III, C.E. (2020). Development and optimization of chromosomally-integrated fluorescent Mycobacterium tuberculosis reporter constructs. Front Microbiol 11. 10.3389/fmicb.2020.591866.

Kumar, P., Arora, K., Lloyd, J.R., Lee, I.Y., Nair, V., Fischer, E., Boshoff, H.I., and Barry, C.E., 3rd (2012). Meropenem inhibits D,D-carboxypeptidase activity in Mycobacterium tuberculosis. Mol Microbiol 86, 367-381. 10.1111/j.1365-2958.2012.08199.x.

Liebschner, D., Afonine, P.V., Baker, M.L., Bunkoczi, G., Chen, V.B., Croll, T.I., Hintze, B., Hung, L.W., Jain, S., McCoy, A.J., et al. (2019). Macromolecular structure determination using X-rays, neutrons and electrons: recent developments in Phenix. Acta Crystallogr D Struct Biol 75, 861-877. 10.1107/S2059798319011471. 
Love, M.I., Huber, W., and Anders, S. (2014). Moderated estimation of fold change and dispersion for RNA-seq data with DESeq2. Genome Biol 15, 550. 10.1186/s13059-014-05508 .

Machowski, E.E., Barichievy, S., Springer, B., Durbach, S.I., and Mizrahi, V. (2007). In vitro analysis of rates and spectra of mutations in a polymorphic region of the Rv0746 PE_PGRS gene of Mycobacterium tuberculosis. J Bacteriol 189, 2190-2195. 10.1128/JB.01647-06.

Manca, C., Tsenova, L., Bergtold, A., Freeman, S., Tovey, M., Musser, J.M., Barry, C.E., 3rd, Freedman, V.H., and Kaplan, G. (2001). Virulence of a Mycobacterium tuberculosis clinical isolate in mice is determined by failure to induce Th1 type immunity and is associated with induction of IFN-alpha /beta. Proc Natl Acad Sci U S A 98, 5752-5757. 10.1073/pnas.091096998.

Mayer, C., and Takiff, H. (2014). The molecular genetics of fluoroquinolone resistance in Mycobacterium tuberculosis. In Molecular Genetics of Mycobacteria, pp. 455-478. 10.1128/9781555818845.ch23.

Murshudov, G.N., Skubak, P., Lebedev, A.A., Pannu, N.S., Steiner, R.A., Nicholls, R.A., Winn, M.D., Long, F., and Vagin, A.A. (2011). REFMAC5 for the refinement of macromolecular crystal structures. Acta Crystallogr D Biol Crystallogr 67, 355-367. 10.1107/S0907444911001314.

Nagaraja, V., Godbole, A.A., Henderson, S.R., and Maxwell, A. (2017). DNA topoisomerase I and DNA gyrase as targets for TB therapy. Drug Discovery Today 22, 510-518. 10.1016/j.drudis.2016.11.006.

Naran, K., Moosa, A., Barry, C.E., Boshoff, H.I.M., Mizrahi, V., and Warner, D.F. (2016). Bioluminescent reporters for rapid mechanism of action assessment in tuberculosis drug discovery. Antimicrob Agents Chemother 60, 6748-6757. 10.1128/AAC.01178-16.

Nicholls, R.A., Tykac, M., Kovalevskiy, O., and Murshudov, G.N. (2018). Current approaches for the fitting and refinement of atomic models into cryo-EM maps using CCP-EM. Acta Crystallogr D Struct Biol 74, 492-505. 10.1107/S2059798318007313.

Ortalo-Magne, A., Lemassu, A., Laneelle, M.A., Bardou, F., Silve, G., Gounon, P., Marchal, G., and Daffe, M. (1996). Identification of the surface-exposed lipids on the cell envelopes of Mycobacterium tuberculosis and other mycobacterial species. J Bacteriol 178, 456-461. 10.1128/jb.178.2.456-461.1996.

Painter, R.E., Adam, G.C., Arocho, M., DiNunzio, E., Donald, R.G.K., Dorso, K., Genilloud, O., Gill, C., Goetz, M., Hairston, N.N., et al. (2015). Elucidation of dnaE as the antibacterial target of the natural product, nargenicin. Chem Biol 22, 1362-1373. 10.1016/j.chembiol.2015.08.015.

Patro, R., Duggal, G., Love, M.I., Irizarry, R.A., and Kingsford, C. (2017). Salmon provides fast and bias-aware quantification of transcript expression. Nature Methods 14, 417-419. 10.1038/nmeth.4197.

Pidot, S.J., and Rizzacasa, M.A. (2020). The nargenicin family of oxa-bridged macrolide antibiotics. Chemistry 26, 2780-2792. 10.1002/chem.201904053.

R Core Team. (2020). R: A language and environment for statistical computing. (R Foundation for Statistical Computing). 
Reiche, M.A., Warner, D.F., and Mizrahi, V. (2017). Targeting DNA replication and repair for the development of novel therapeutics against tuberculosis. Front Mol Biosci 4, 75. 10.3389/fmolb.2017.00075.

Rock, J.M., Hopkins, F.F., Chavez, A., Diallo, M., Chase, M.R., Gerrick, E.R., Pritchard, J.R., Church, G.M., Rubin, E.J., Sassetti, C.M., et al. (2017). Programmable transcriptional repression in mycobacteria using an orthogonal CRISPR interference platform. Nat Microbiol 2, 16274. 10.1038/nmicrobiol.2016.274.

Rock, J.M., Lang, U.F., Chase, M.R., Ford, C.B., Gerrick, E.R., Gawande, R., Coscolla, M., Gagneux, S., Fortune, S.M., and Lamers, M.H. (2015). DNA replication fidelity in Mycobacterium tuberculosis is mediated by an ancestral prokaryotic proofreader. Nat Genet 47, 677-681. 10.1038/ng.3269.

RStudio Team. (2020). RStudio: Integrated development for R (PBC).

Sayols, S., Scherzinger, D., and Klein, H. (2016). dupRadar: a Bioconductor package for the assessment of PCR artifacts in RNA-Seq data. BMC Bioinformatics 17, 428. 10.1186/s12859016-1276-2.

Schindelin, J., Arganda-Carreras, I., Frise, E., Kaynig, V., Longair, M., Pietzsch, T., Preibisch, S., Rueden, C., Saalfeld, S., Schmid, B., et al. (2012). Fiji: an open-source platform for biological-image analysis. Nature Methods 9, 676-682. 10.1038/nmeth.2019.

Shamputa, I.C., Lee, J., Allix-Beguec, C., Cho, E.J., Lee, J.I., Rajan, V., Lee, E.G., Min, J.H., Carroll, M.W., Goldfeder, L.C., et al. (2010). Genetic diversity of Mycobacterium tuberculosis isolates from a tertiary care tuberculosis hospital in South Korea. J Clin Microbiol 48, 387-394. 10.1128/JCM.02167-09.

Sinha, K.M., Unciuleac, M.C., Glickman, M.S., and Shuman, S. (2009). AdnAB: a new DSBresecting motor-nuclease from mycobacteria. Genes Dev 23, 1423-1437. 10.1101/gad.1805709.

Snapper, S.B., Melton, R.E., Mustafa, S., Kieser, T., and Jacobs, W.R., Jr. (1990). Isolation and characterization of efficient plasmid transformation mutants of Mycobacterium smegmatis. Mol Microbiol 4, 1911-1919. 10.1111/j.1365-2958.1990.tb02040.x.

Sohng, J.K., Yamaguchi, T., Seong, C.N., Baik, K.S., Park, S.C., Lee, H.J., Jang, S.Y., Simkhada, J.R., and Yoo, J.C. (2008). Production, isolation and biological activity of nargenicin from Nocardia sp. CS682. Arch Pharm Res 31, 1339-1345. 10.1007/s12272-0012115-0.

Subramaniya, S.R.M.V., Terashi, G., and Kihara, D. (2021). Super-Resolution cryo-EM Maps with 3D deep generative networks. bioRxiv. 10.1101/2021.01.12.426430.

Szklarczyk, D., Gable, A.L., Lyon, D., Junge, A., Wyder, S., Huerta-Cepas, J., Simonovic, M., Doncheva, N.T., Morris, J.H., Bork, P., et al. (2018). STRING v11: protein-protein association networks with increased coverage, supporting functional discovery in genome-wide experimental datasets. Nucleic Acids Res 47, D607-D613. 10.1093/nar/gky1131.

Toste Rego, A., Holding, A.N., Kent, H., and Lamers, M.H. (2013). Architecture of the Pol IIIclamp-exonuclease complex reveals key roles of the exonuclease subunit in processive DNA synthesis and repair. EMBO J 32, 1334-1343. 10.1038/emboj.2013.68.

Tullius, M.V., Nava, S., and Horwitz, M.A. (2019). PPE37 Is essential for Mycobacterium tuberculosis heme-iron acquisition (HIA), and a defective PPE37 in Mycobacterium bovis BCG prevents HIA. Infect Immun 87. 10.1128/iai.00540-18. 
Valway, S.E., Sanchez, M.P., Shinnick, T.F., Orme, I., Agerton, T., Hoy, D., Jones, J.S., Westmoreland, H., and Onorato, I.M. (1998). An outbreak involving extensive transmission of a virulent strain of Mycobacterium tuberculosis. $N$ Engl J Med 338, 633-639. 10.1056/NEJM199803053381001.

Wang, L., Nie, J., Sicotte, H., Li, Y., Eckel-Passow, J.E., Dasari, S., Vedell, P.T., Barman, P., Wang, L., Weinshiboum, R., et al. (2016). Measure transcript integrity using RNA-seq data. BMC Bioinformatics 17, 58. 10.1186/s12859-016-0922-z.

Warner, D.F., Ndwandwe, D.E., Abrahams, G.L., Kana, B.D., Machowski, E.E., Venclovas, C., and Mizrahi, V. (2010). Essential roles for imuA'- and imuB-encoded accessory factors in DnaE2-dependent mutagenesis in Mycobacterium tuberculosis. Proc Natl Acad Sci U S A 107, 13093-13098. 10.1073/pnas.1002614107.

WHO. (2021). Global Tuberculosis Report 2021 (World Health Organisation).

Wing, R.A., Bailey, S., and Steitz, T.A. (2008). Insights into the replisome from the structure of a ternary complex of the DNA polymerase III alpha-subunit. J Mol Biol 382, 859-869. 10.1016/j.jmb.2008.07.058.

Young, K., Olsen, D.B., Singh, S.B., Su, J., Wilkening, R.R., Apgar, J.M., Meng, D., Parker, D., Mandal, M., Yang, L., et al. (2017). Nargenicin compounds and uses thereof as antibacterial agents. United States patent US20170305924A1, 2017/10/26/.

Zhang, K. (2016). Gctf: Real-time CTF determination and correction. J Struct Biol 193, 1-12. 10.1016/j.jsb.2015.11.003.

Zivanov, J., Nakane, T., Forsberg, B.O., Kimanius, D., Hagen, W.J., Lindahl, E., and Scheres, S.H. (2018). New tools for automated high-resolution cryo-EM structure determination in RELION-3. elife 7. 10.7554/eLife.42166. 
bioRxiv preprint doi: https://doi.org/10.1101/2021.10.27.466036; this version posted October 27, 2021. The copyright holder for this preprint (which was not certified by peer review) is the author/funder, who has granted bioRxiv a license to display the preprint in perpetuity. It is made available under aCC-BY-NC-ND 4.0 International license.

\section{Figure 1.}

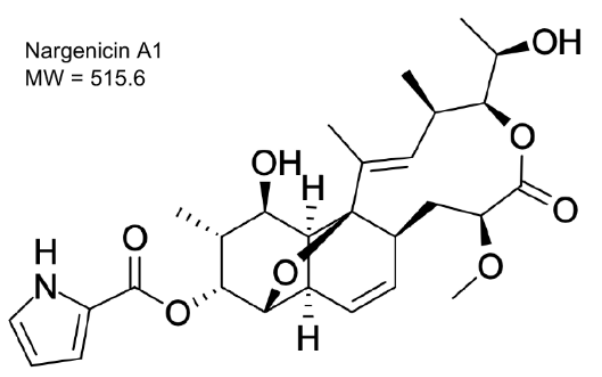

B

B. subtilis - ATCC 6633

M. luteus - ATCC 9341

S. aureus - KCTC 1928

S. aureus - MRSA 693E -

Mtb - H37Rv (7H9/OADC/Tw)

Mtb - H37Rv (7H9/Glu/ADC/Tw) -

Mtb - H37Rv (7H9/OADC/Tx)

Mtb - H37Rv (Gast/Tw)

Mtb - CDC1551(7H9/OADC/Tw)

Mtb - HN878(7H9/OADC/Tw) Msm $-\mathrm{mc}^{2} 155$ (7H9/OADC/Tw)

C

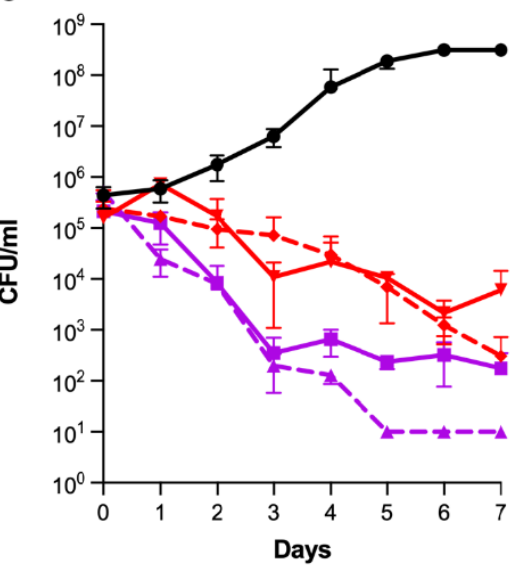

D

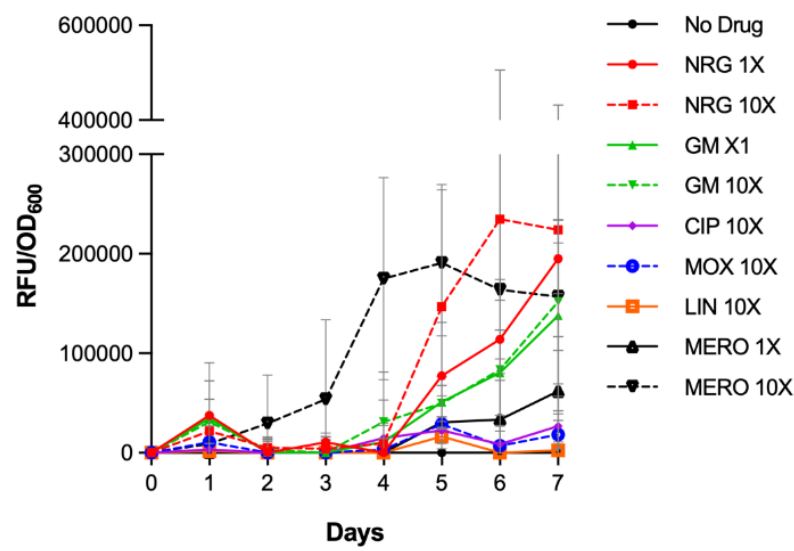


bioRxiv preprint doi: https://doi.org/10.1101/2021.10.27.466036; this version posted October 27, 2021. The copyright holder for this preprint (which was not certified by peer review) is the author/funder, who has granted bioRxiv a license to display the preprint in perpetuity. It is made available under aCC-BY-NC-ND 4.0 International license.

Figure 2
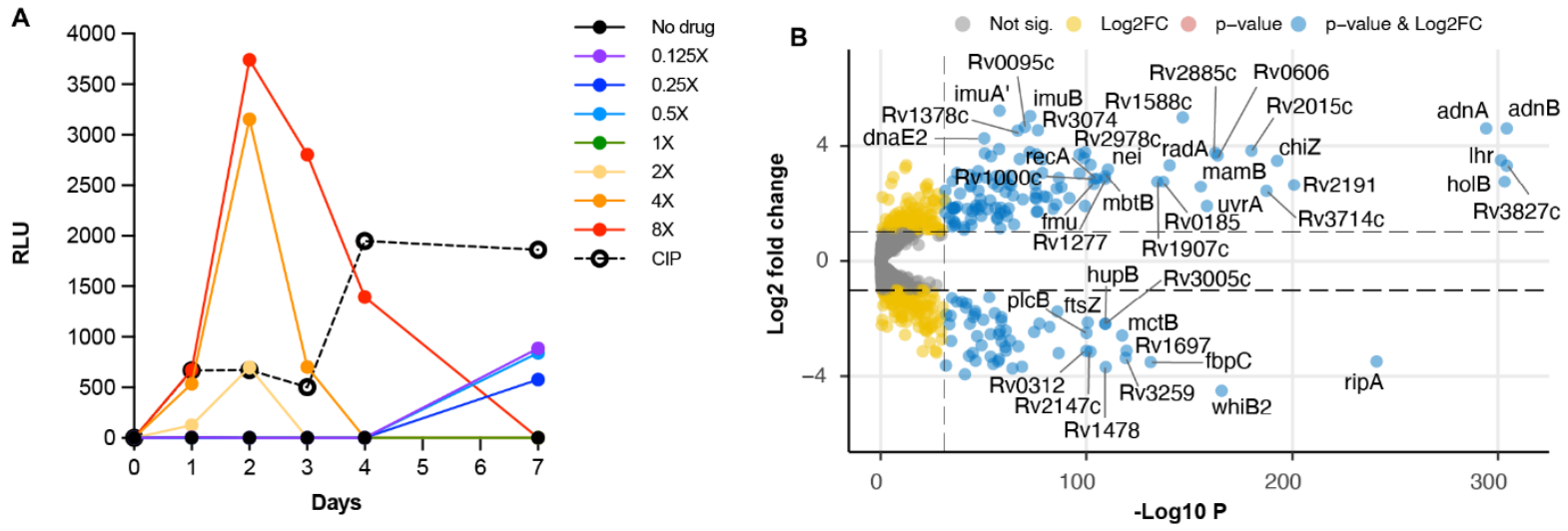

C

$$
\begin{array}{l|l}
\text { Amino acid metabolism and transport } & \text { Lipid metabolism } \\
\text { Cell envelope biogenesis } & \text { Nucleotide metabolism and transport } \\
\text { Coenzyme metabolism } & \text { Replication and repair } \\
\text { Energy production and conversion } & \text { Translation }
\end{array}
$$

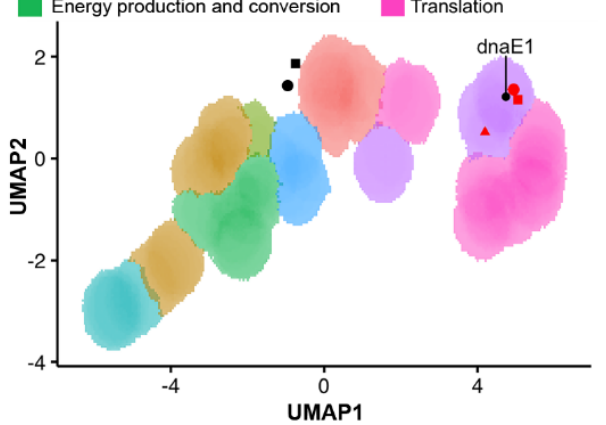

D

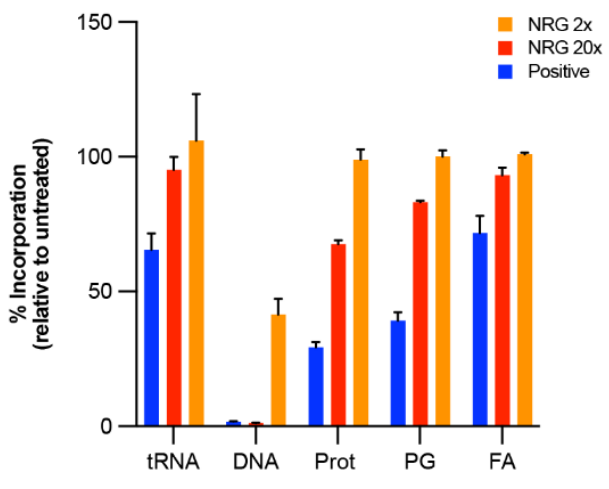


bioRxiv preprint doi: https://doi.org/101101/2021.10.27.466036; this version posted October 27, 2021. The copyright holder for this preprint (which was not certified by peer review) is the author/funder, who has granted bioRxiv a license to display the preprint in perpetuity. It is made available under aCC-BY-NC-ND 4.0 International license.

Figure 3

A sgRNA position 6 11 $13-3555$

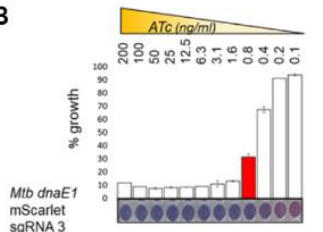

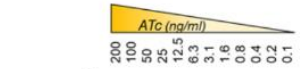

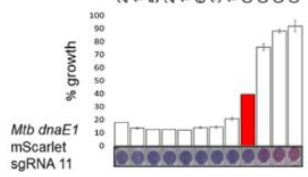

ATe(ng/m)

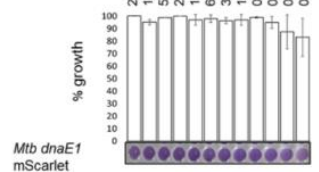

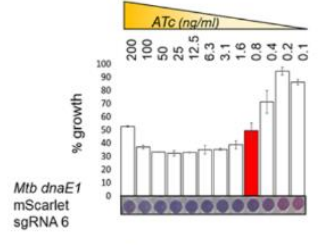

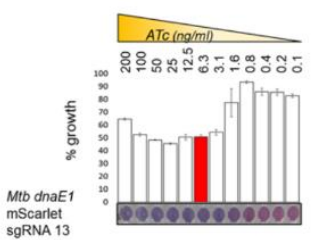

mScarlet
sgRNA 13
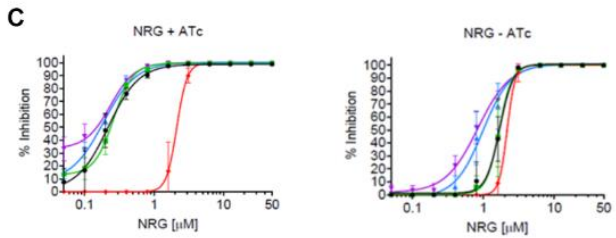

$C I P+A T C$

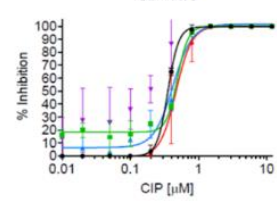

INH +ATC

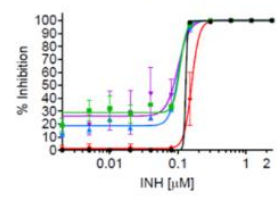

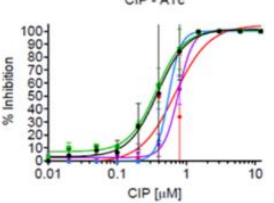

INH - ATC

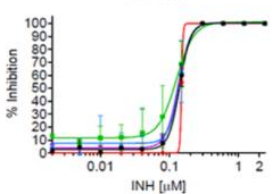


bioRxiv preprint doi: https://doi.org/10.1101/2021.10.27.466036; this version posted October 27, 2021. The copyright holder for this preprint (which was not certified by peer review) is the author/funder, who has granted bioRxiv a license to display the preprint in perpetuity. It is made available under aCC-BY-NC-ND 4.0 International license.

\section{Figure 4}

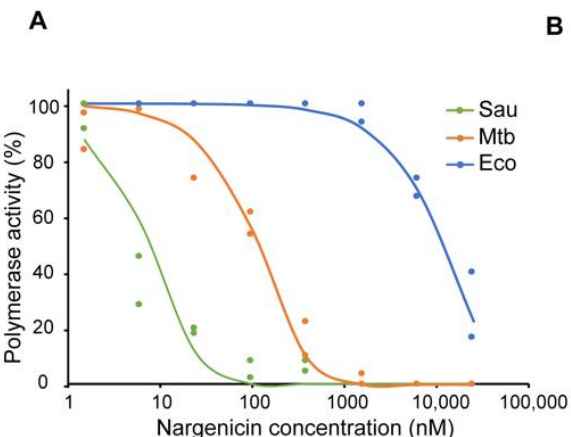

D

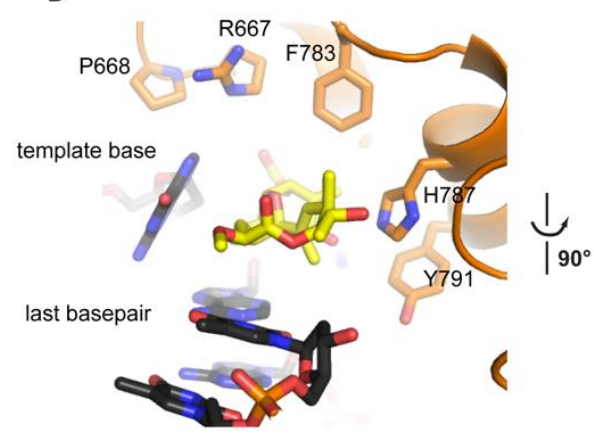

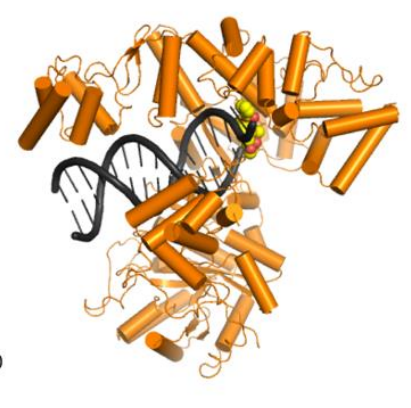

C

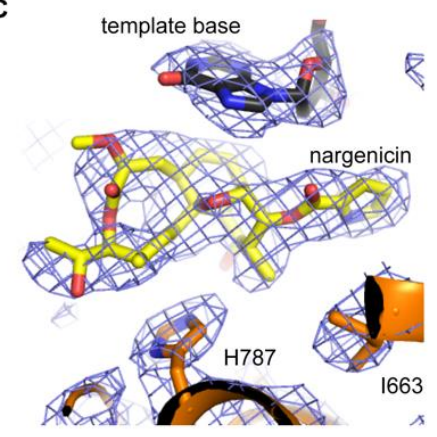

$\mathbf{F}$

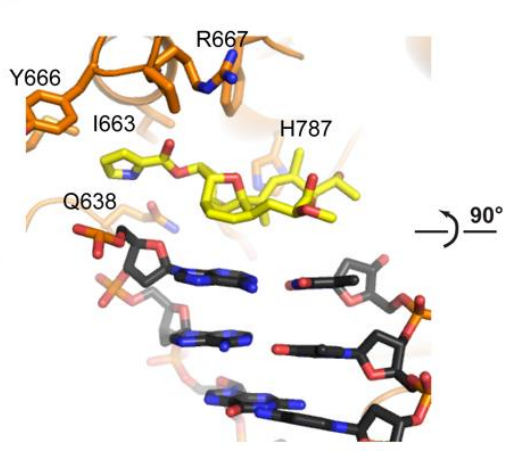

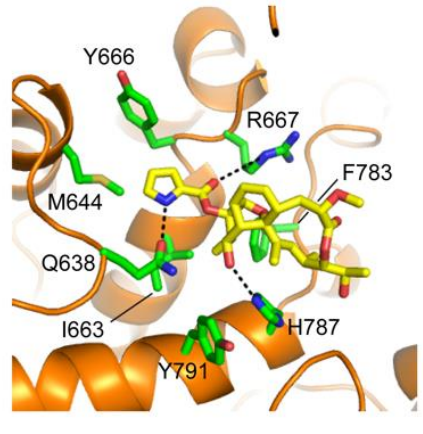

\section{Figure 5}

A

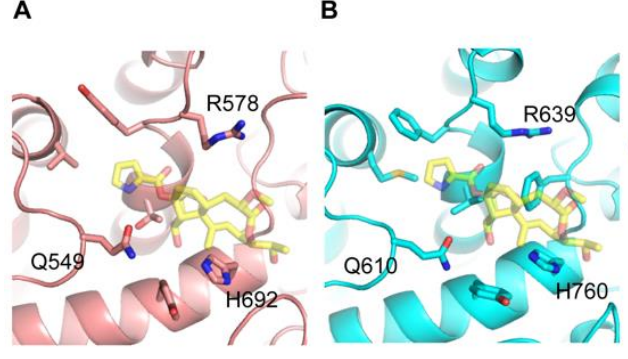

C

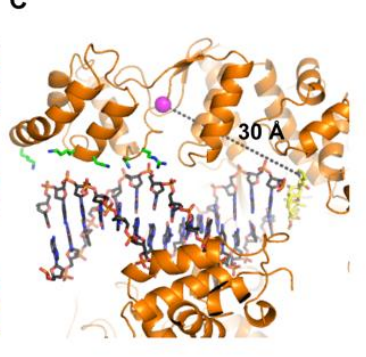

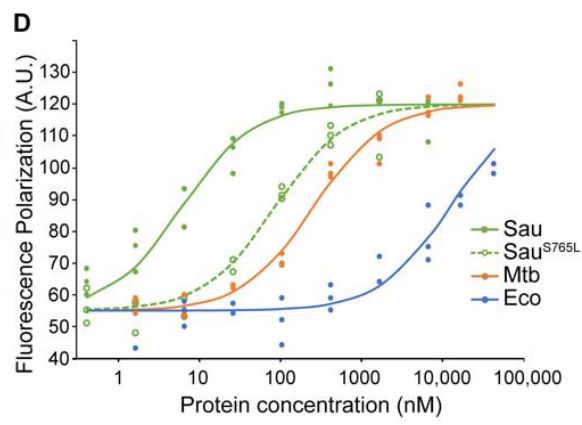




\section{Key resources table}

\begin{tabular}{|c|c|c|}
\hline REAGENT or RESOURCE & SOURCE & IDENTIFIER \\
\hline \multicolumn{3}{|l|}{ Antibodies } \\
\hline \multicolumn{3}{|l|}{ Bacterial and virus strains } \\
\hline Escherichia coli DH5a & $\begin{array}{l}\text { Thermo Fisher } \\
\text { Scientific }\end{array}$ & Cat\#18265017 \\
\hline Escherichia coli BL21 & New England Biolabs & Cat\#C2530H \\
\hline Mycobacterium smegmatis $\mathrm{mc}^{2155}$ & (Snapper et al., 1990) & $\mathrm{N} / \mathrm{A}$ \\
\hline Mycobacterium tuberculosis H37Rv (H37RvMA) & (loerger et al., 2010) & $\mathrm{N} / \mathrm{A}$ \\
\hline Mycobacterium tuberculosis CDC1551 & $\begin{array}{l}\text { Clinical isolate } \\
\text { (Valway et al., 1998) }\end{array}$ & $\mathrm{N} / \mathrm{A}$ \\
\hline Mycobacterium tuberculosis HN878 & $\begin{array}{l}\text { Clinical isolate } \\
\text { (Manca et al., 2001) }\end{array}$ & $\mathrm{N} / \mathrm{A}$ \\
\hline Mycobacterium tuberculosis K04b00DS & $\begin{array}{l}\text { Clinical isolate } \\
\text { (Shamputa et al., } \\
\text { 2010) }\end{array}$ & $\mathrm{N} / \mathrm{A}$ \\
\hline Mycobacterium tuberculosis NIH_KA31b00DS & $\begin{array}{l}\text { Clinical isolate } \\
\text { (Shamputa et al., } \\
2010)\end{array}$ & $\mathrm{N} / \mathrm{A}$ \\
\hline Mycobacterium tuberculosis K14b00DS & $\begin{array}{l}\text { Clinical isolate } \\
\text { (Shamputa et al., } \\
\text { 2010) }\end{array}$ & $\mathrm{N} / \mathrm{A}$ \\
\hline Mycobacterium tuberculosis K29b00MR & $\begin{array}{l}\text { Clinical isolate } \\
\text { (Shamputa et al., } \\
\text { 2010) }\end{array}$ & $\mathrm{N} / \mathrm{A}$ \\
\hline Mycobacterium tuberculosis K33b00MR & $\begin{array}{l}\text { Clinical isolate } \\
\text { (Shamputa et al., } \\
\text { 2010) }\end{array}$ & $\mathrm{N} / \mathrm{A}$ \\
\hline Mycobacterium tuberculosis K37b00XR & $\begin{array}{l}\text { Clinical isolate } \\
\text { (Shamputa et al., } \\
\text { 2010) }\end{array}$ & $\mathrm{N} / \mathrm{A}$ \\
\hline Mycobacterium tuberculosis K32b00MR & $\begin{array}{l}\text { Clinical isolate } \\
\text { (Shamputa et al., } \\
\text { 2010) }\end{array}$ & $\mathrm{N} / \mathrm{A}$ \\
\hline \multicolumn{3}{|l|}{ Biological samples } \\
\hline \multicolumn{3}{|l|}{ Chemicals, peptides, and recombinant proteins } \\
\hline Nargenicin A1, Antibiotic agent & Abcam & Cat\#AB144312 \\
\hline Griselimycin, Antibiotic agent & $\begin{array}{l}\text { A gift from Prof. Rolf } \\
\text { Müller \& Dr. Jennifer } \\
\text { Herrmann, Helmholtz } \\
\text { Institute for } \\
\text { Pharmaceutical } \\
\text { Research Saarland }\end{array}$ & $\mathrm{N} / \mathrm{A}$ \\
\hline Levofloxacin, Antibiotic agent & Sigma-Aldrich (Merck) & Cat\#28266 \\
\hline Ofloxacin, Antibiotic agent & Sigma-Aldrich (Merck) & Cat\#08757 \\
\hline Ciprofloxacin, Antibiotic agent & Sigma-Aldrich (Merck) & Cat\#17850 \\
\hline \multicolumn{3}{|l|}{ Isoniazid, Antibiotic agent } \\
\hline Mitomycin $\mathrm{C}$ & Sigma-Aldrich (Merck) & Cat\# 10107409001 \\
\hline Streptomycin, Antibiotic agent & Sigma-Aldrich (Merck) & Cat\#85886 \\
\hline D-cycloserine, Antibiotic agent & Sigma-Aldrich (Merck) & Cat\#C6880 \\
\hline Aphidicolin, Antibiotic agent & Sigma-Aldrich (Merck) & Cat\#89458 \\
\hline$\left[6-{ }^{3} \mathrm{H}\right]$-uracil & Moravek & Cat\#MT656 \\
\hline $\mathrm{L}-[2,3,4,5,6-3 \mathrm{H}]-$ phenylalanine & $\begin{array}{l}\text { American } \\
\text { Radiolabeled } \\
\text { Chemicals }\end{array}$ & Cat\#ART1546 \\
\hline
\end{tabular}




\begin{tabular}{|c|c|c|}
\hline$\left[1,6-{ }^{3} \mathrm{H}\right]-\mathrm{N}$-acetyl-D-glucosamine & $\begin{array}{l}\text { American } \\
\text { Radiolabeled } \\
\text { Chemicals }\end{array}$ & Cat\#ART0142 \\
\hline$\left[1-{ }^{14} \mathrm{C}\right]$-acetic acid, sodium salt & Moravek & Cat\#MC125 \\
\hline \multicolumn{3}{|l|}{ Critical commercial assays } \\
\hline alamarBlue ${ }^{\mathrm{TM}}$ Cell Viability Reagent & $\begin{array}{l}\text { Thermo Fisher } \\
\text { Scientific }\end{array}$ & Cat\#DAL1100 \\
\hline Qiazol Lysis Reagent & Qiagen & Cat\#79306 \\
\hline Direct-zol RNA MiniPrep kit & Zymo Research & Cat\#R2050 \\
\hline TURBO DNA-free kit & Ambion & Cat\#AM1907 \\
\hline Bioanalyzer RNA 6000 Nano Kit and Chips & Agilent & Cat\#5067-1511 \\
\hline SuperScript ${ }^{\circledR}$ IV Reverse Transcriptase & $\begin{array}{l}\text { Thermo Fischer } \\
\text { Scientific }\end{array}$ & Cat\#18090010 \\
\hline Power SYBR $®$ Green PCR master mix & $\begin{array}{l}\text { Thermo Fischer } \\
\text { Scientific }\end{array}$ & Cat\#4367659 \\
\hline \multicolumn{3}{|l|}{ Deposited data } \\
\hline Transcriptomics datasets & This paper & $\begin{array}{l}\text { NCBI SRA: } \\
\text { PRJNA722614 }\end{array}$ \\
\hline Atomic models & This paper & $\begin{array}{l}\text { Protein Data Bank: } \\
\text { PDB XXX (pending) }\end{array}$ \\
\hline Cryo-EM maps & This paper & $\begin{array}{l}\text { Electron Microscopy } \\
\text { Database: EMD YYY } \\
\text { (pending) }\end{array}$ \\
\hline \multicolumn{3}{|l|}{ Experimental models: Cell lines } \\
\hline \multicolumn{3}{|l|}{ Experimental models: Organisms/strains } \\
\hline Mycobacterium smegmatis $\mathrm{mc}^{2} 155 \Delta r e c A$ & $\begin{array}{l}\text { (Machowski et al., } \\
\text { 2007) }\end{array}$ & $\mathrm{N} / \mathrm{A}$ \\
\hline Mycobacterium smegmatis $\mathrm{mc}^{2} 155 \Delta d n a E 2$ & (Warner et al., 2010) & $\mathrm{N} / \mathrm{A}$ \\
\hline $\begin{array}{l}\text { Mycobacterium smegmatis mc } \text { M }^{2} 55 \mathrm{P}_{\text {uv15-Tet-dnaE1- }} \\
\text { MYC::L5 }\end{array}$ & (Rock et al., 2015) & $\mathrm{N} / \mathrm{A}$ \\
\hline Mycobacterium tuberculosis H37Rv-GFP & $\begin{array}{l}\text { (Abrahams et al., } \\
\text { 2012) }\end{array}$ & $\mathrm{N} / \mathrm{A}$ \\
\hline Mycobacterium tuberculosis H37Rv PrecA-LUX & (Naran et al., 2016) & $\mathrm{N} / \mathrm{A}$ \\
\hline $\begin{array}{l}\text { Mycobacterium tuberculosis H37Rv } \mathrm{P}_{\text {uv15-Tet-dnaE1- }} \\
\text { MYC::L5 }\end{array}$ & This paper & $\mathrm{N} / \mathrm{A}$ \\
\hline Mycobacterium tuberculosis H37Rv $\Delta$ dnaE2 & (Boshoff et al., 2003) & N/A \\
\hline Mycobacterium tuberculosis H37Rv mScarlet & This paper & $\mathrm{N} / \mathrm{A}$ \\
\hline Mycobacterium tuberculosis H37Rv dnaE1 sgRNA 3 & This paper & $\mathrm{N} / \mathrm{A}$ \\
\hline Mycobacterium tuberculosis H37Rv dnaE1 sgRNA 6 & This paper & $\mathrm{N} / \mathrm{A}$ \\
\hline Mycobacterium tuberculosis H37Rv dnaE1 sgRNA 11 & This paper & $\mathrm{N} / \mathrm{A}$ \\
\hline Mycobacterium tuberculosis H37Rv dnaE1 sgRNA 13 & This paper & $\mathrm{N} / \mathrm{A}$ \\
\hline \multicolumn{3}{|l|}{ Oligonucleotides } \\
\hline \multicolumn{3}{|l|}{$\begin{array}{l}\text { See Table S3 for information on primers and other } \\
\text { oligonucleotides used in this study }\end{array}$} \\
\hline \multicolumn{3}{|l|}{ Recombinant DNA } \\
\hline $\mathrm{P}_{\text {uv15-Tet }}$-dnaE1-MYC::L5 & (Rock et al., 2015) & $\mathrm{N} / \mathrm{A}$ \\
\hline pLJR965 & (Rock et al., 2017) & $\mathrm{N} / \mathrm{A}$ \\
\hline Giles attB: $P_{\text {left }}$ mScarlet & (Kolbe et al., 2020) & $\mathrm{N} / \mathrm{A}$ \\
\hline pUC19-GI & (Kolbe et al., 2020) & $\mathrm{N} / \mathrm{A}$ \\
\hline pLJR965_dnaE1_sgRNA3 & This paper & $\mathrm{N} / \mathrm{A}$ \\
\hline pLJR965_dnaE1_sgRNA6 & This paper & $\mathrm{N} / \mathrm{A}$ \\
\hline pLJR965_dnaE1_sgRNA11 & This paper & $\mathrm{N} / \mathrm{A}$ \\
\hline pLJR965_dnaE1_sgRNA13 & This paper & $\mathrm{N} / \mathrm{A}$ \\
\hline
\end{tabular}




\begin{tabular}{|c|c|c|}
\hline Microsoft Excel & Microsoft & $\mathrm{N} / \mathrm{A}$ \\
\hline Prism 9 & Graph Pad & $\mathrm{N} / \mathrm{A}$ \\
\hline SoftMax Pro Software & Molecular Devices & $\mathrm{N} / \mathrm{A}$ \\
\hline Clariostar Microplate Reader Software & BMG LABTECH & $\mathrm{N} / \mathrm{A}$ \\
\hline ZEN (blue) Imaging Software & ZEISS & $\mathrm{N} / \mathrm{A}$ \\
\hline FIJI & $\begin{array}{l}\text { (Schindelin et al., } \\
\text { 2012) }\end{array}$ & https://fiji.sc \\
\hline Microbe J Plugin & (Ducret et al., 2016) & $\begin{array}{l}\text { https://www.microbej } \\
\text {.com }\end{array}$ \\
\hline Spatial UMAP Analysis & (de Wet et al., 2020) & https://osf.io/pdcw2/ \\
\hline R ver. 4.1.0 & (R Core Team, 2020) & $\begin{array}{l}\text { https://www.r- } \\
\text { project.org/ }\end{array}$ \\
\hline RStudio ver. 1.4.1717 & (RStudio Team, 2020) & $\begin{array}{l}\text { https://www.rstudio.c } \\
\text { om }\end{array}$ \\
\hline FastQC & (Andrews, 2010) & $\begin{array}{l}\text { https://www.bioinfor } \\
\text { matics.babraham.ac. } \\
\text { uk/projects/fastqc/ }\end{array}$ \\
\hline TrimGalore & $\mathrm{N} / \mathrm{A}$ & $\begin{array}{l}\text { https://www.bioinfor } \\
\text { matics.babraham.ac. } \\
\text { uk/projects/trim_galo } \\
\text { re/ }\end{array}$ \\
\hline RSeQC & (Wang et al., 2016) & $\begin{array}{l}\text { http://rseqc.sourcefo } \\
\text { rge.net }\end{array}$ \\
\hline dupRadar & (Sayols et al., 2016) & $\begin{array}{l}\text { https://bioconductor. } \\
\text { org/packages/releas } \\
\text { e/bioc/html/dupRada } \\
\text { r.html }\end{array}$ \\
\hline MultiQC & (Ewels et al., 2016) & https://multiqc.info \\
\hline Salmon & (Patro et al., 2017) & $\begin{array}{l}\text { https://combine- } \\
\text { lab.github.io/salmon/ }\end{array}$ \\
\hline DESeq2 & (Love et al., 2014) & $\begin{array}{l}\text { https://bioconductor. } \\
\text { org/packages/releas } \\
\text { e/bioc/html/DESeq2. } \\
\text { html }\end{array}$ \\
\hline STRING ver. $11.0 \mathrm{~b}$ & $\begin{array}{l}\text { (Szklarczyk et al., } \\
\text { 2018) }\end{array}$ & https://string-db.org/ \\
\hline EPU (Cryo-EM Single Particle Analysis Software) & $\begin{array}{l}\text { Thermo Fisher } \\
\text { Scientific }\end{array}$ & $\mathrm{N} / \mathrm{A}$ \\
\hline RELION 3.1 & (Zivanov et al., 2018) & $\mathrm{N} / \mathrm{A}$ \\
\hline gCTF v1.06 & (Zhang, 2016) & $\mathrm{N} / \mathrm{A}$ \\
\hline Coot & (Emsley et al., 2010) & $\begin{array}{l}\text { https://pemsley.githu } \\
\text { b.io/coot/blog/2021/0 } \\
\text { 2/02/release- } \\
\text { 0.9.4.1.html } \\
\end{array}$ \\
\hline REFMAC5 & $\begin{array}{l}\text { (Murshudov et al., } \\
\text { 2011) }\end{array}$ & $\begin{array}{l}\text { https://www2.mrc- } \\
\text { Imb.cam.ac.uk/group } \\
\text { s/murshudov/content } \\
\text { /refmac/refmac.html }\end{array}$ \\
\hline CCPEM-suite & (Nicholls et al., 2018) & \\
\hline Phenix & $\begin{array}{l}\text { (Liebschner et al., } \\
\text { 2019). }\end{array}$ & $\begin{array}{l}\text { http://www.phenix- } \\
\text { online.org }\end{array}$ \\
\hline PyMOL & Schrödinger & https://pymol.org/ \\
\hline \multicolumn{3}{|l|}{ Other } \\
\hline
\end{tabular}

